\title{
EL LIBRO DE CORRESPONDENCIA DE DON BLAS MARÍA RUBIÑOS (1790-1807): PRESENTACIÓN TEMÁTICA DE SU CONTENIDO Y TRANSCRIPCIÓN ${ }^{1}$
}

\author{
Por \\ ANTONIO PRESEDO GARAZO
}

\section{RESUMEN}

El estudio de la documentación conservada en los archivos familiares privados y en los archivos nobiliarios ha merecido una especial atención en el contexto historiográfico europeo en los últimos años. En el presente artículo nos hemos aproximado al libro de correspondencia del hidalgo gallego don Blas María Rubiños para el período histórico comprendido entre 1790 y 1807 . Así, hemos elaborado en primer lugar una reflexión sobre el estado actual en que se halla la investigación histórica gallega en relación con esta temática específica; además de una presentación breve del origen histórico de la casa de los Rubiños de Vilanova de Lourenzá. Y, a continuación, hemos procedido a transcribir en su integridad dicho documento debido a la riqueza informativa de su contenido.

${ }^{1}$ El presente artículo ha sido realizado gracias a la financiación de una beca doctoral de Humanidades que la Fundación Caja Madrid ha concedido a quien lo suscribe.

«CUADERNOS DE ESTUDIOS GALLEGOS», Tomo L, Fascículo 116, Santiago 2003. 


\title{
PALABRAS CLAVE
}

Archivos nobiliarios, archivos familiares privados, correspondencia privada, hidalguía/hidalgo.

\begin{abstract}
Research in personal family files and noble files documents has deserved special attention in European historiographic context in recent years. In this paper, we have approximated to the Galician hidalgo Blas Maria Rubiños' correspondence book during the historical period from 1790 to 1807 . So then, firstly, we have reflected on the present condition of the historical research work in Galicia in relation to this specific subject, besides a short explanation of the house of Rubiños of Vilanova de Lourenzá's historic origin. Then, we have transcribed the whole document because of its contens' importance.
\end{abstract}

\section{KEYWORDS}

Noble files, personal family files, private correspondance, hidalguía/ hidalgo.

\section{PRESENTACIÓN DEL DOCUMENTO}

Los archivos nobiliarios, también conocidos como archivos familiares o patrimoniales privados han despertado un notable interés en los últimos años entre la comunidad científica de historiadores gallegos ${ }^{2}$. Debido al estudio del estamento nobiliario, fundamentalmente durante el Antiguo

\footnotetext{
${ }^{2}$ Sobre todo, a raíz de la publicación en 1982 de la tesis de Ramón Villares Paz, en la que al abordar el estudio de la propiedad de la tierra en Galicia, procedió al estudio de la consolidación de los patrimonios hidalgos valiéndose de archivos privados. Vid. VILLARES PAZ, R.: La propiedad de la tierra en Galicia, 1500-1936, Madrid, 1982.
}

«CUADERNOS DE ESTUdIOS GALLEGOS», Tomo L, Fascículo 116, Santiago 2003. 
Régimen y el siglo XIX, que a lo largo de los tres lustros comprendidos entre 1985 y 2000 ha experimentado un desarrollo notable, distintos investigadores históricos han ido accediendo a una parte nada desdeñable de esta tipología de fuentes documentales. Principalmente depositados en instituciones públicas, tales como el Archivo Histórico Provincial de Ourense $^{3}$, el Provincial de Lugo ${ }^{4}$, el del Reino de Galicia en A Coruña ${ }^{5}$, el Universitario de Santiago ${ }^{6}$, o en la Biblioteca del Museo Provincial de

\footnotetext{
${ }^{3}$ Para una aproximación a los fondos privados depositados en dicho archivo en la sección Casas Particulares, vid. GALLEGO DOMÍNGUEZ, O.: Archivo Histórico Provincial de Orense. Guia del investigador, Ourense, 1977. Entre los archivos familiares privados depositados en dicha sección que ya han merecido un interés previo por parte de los historiadores, podríamos citar los del Pazo de San Damián, y las casas de Fontefiz, Lorenzana, Noceda y Outarelo. Vid. FERRO COUSELO, J.: «'Gente llana con ventura'. Los Boanes», Boletín Auriense, II (1972); GARCÍA TATO, I.: Vilanova, Outarelo y San Francisco Blanco. Monografia histórica de una parroquia gallega, Barco de Valdeorras, 1999; LEIRÓS DE LA PEÑA, P.: La Casa de Fontefiz (Contribución al estudio de la hidalguia gallega), Santiago, 1986, memoria de licenciatura inédita; PRESEDO GARAZO, A.: Dueños y señores de casas, torres y pazos, 1500-1900 (Contribución al estudio de la fidalguía gallega), Santiago, 2001, tesis doctoral inédita; y QUIROGA

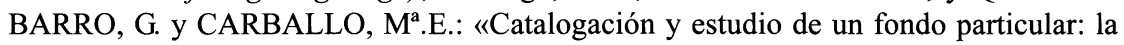
casa de Lorenzana», Boletín Auriense, XIV-XV (1986).

${ }^{4}$ Especial interés merecen los fondos del Conde de Pallares estudiados por X.R. Veiga Alonso. Vid. sus obras Progreso, Prensa e Ferrocarril en Galicia. A Actividade do Conde de Pallares (1855-1883), Lugo, 1996, y O Conde de Pallares e o seu tempo, 1828-1908. Aproximación ó activismo das elites na Galicia decimonónica, Lugo, 1999.

${ }^{5}$ Nos referimos al fondo de los Ozores-Prado del Marquesado de San Martiño de Ombreiro estudiado por MÍGUEZ RODRÍGUEZ, V.M.: A fidalguía galega: un breve enxergar histórico através da Casa de san Fiz de Asma e agregadas no Antigo Réxime, Santiago, 1997, y A fidalguía galega: Aproximación á xénese, desenvolvimento e consolidación dunha elite socio-económica no Antigo Réxime, Santiago, 1999, tesis doctoral inédita.

${ }^{6}$ En su sección Fondos Privados, dentro de los cuales merece ser destacado el archivo de la Casa de Montaos (estudiado por quien suscribe este trabajo en su tesis doctoral), así como una copia microfilmada de los fondos del Archivo Ducal de Medinaceli referidos a Galicia, estudiados por Gonzalo F. Fernández Suárez para la Edad Media (vid. La Casa de Ribadavia, Santiago, 1999, memoria de licenciatura inédita) y parcialmente para el Antiguo Régimen por $M^{a}$.L. García Acuña (Vid. «Unha primeira aproximación ós ingresos do estado de Ribadavia no século XVIII», en Historia Nova III, Santiago, 1993, «El Estado de Ribadavia: formas de cesión y administración del dominio señorial», Obradoiro de Historia Moderna, 4 (1995), y «Mecanismos de control señorial. Los juicios de residencia en el Estado de Ribadavia», Obradoiro de Historia Moderna, 5 (1996)).
}

«CUADERNOS DE ESTUDIOS GALLEGOS», Tomo L, Fascículo 116, Santiago 2003. 
Pontevedra ${ }^{7}$, ello no ha impedido que también se hayan analizado los contenidos de otros fondos -igualmente importantes, y en ocasiones de idéntico volumen informativo- todavía conservados en manos privadas ${ }^{8}$. Nos interesa destacar estas investigaciones, porque poco a poco, con el estudio de dichos archivos familiares privados -y sobre todo con su crítica-, han ido profundizando en el conocimiento general que hasta el momento se tenía de ellos, mereciendo especial atención el análisis de los distintos fondos documentales que albergan, así como los evidentes obstáculos que presentan en conjunto. Ya hemos tenido ocasión de referirnos anteriormente a estas dos últimas cuestiones señaladas, al referirnos a los archivos de las casas de Vilarxoán (Sarria), Fraga (Friol) y Rego do Pazo (Boimorto), tres modestas casas solariegas de la Galicia interior, cuya organización documental presentaba en sus orígenes un aspecto ciertamente caótico9. De hecho, ni siquiera la acertada propuesta de catalogación de fondos privados de Olga Gallego Domínguez ${ }^{10}$ había resultado eficaz a la hora de proceder al reordenamiento de la documentación, por lo que se hizo preciso decidirse por un ordenamiento cronológico por casas combinado con un fichero cronológico-temático.

Los archivos familiares privados, y sobre todo los procedentes de la hidalguía rural, se presentan pues como un complejo mundo al que el

\footnotetext{
${ }^{7}$ Concretamente, merece especial interés la documentación perteneciente a la Casa de Soutomaior.

${ }^{8}$ Entre los autores que se han decantado por esta línea investigadora, habría que destacar entre las obras más sobresalientes, a BARREIRO MALLÓN, B.: «El dominio de la familia Porras y la evolución de las rentas agrarias en la Tierra de Santiago», en VV.AA.: Obradoiro de Historia Moderna. Homenaje al Prof. Antonio Eiras Roel, Santiago, 1990; DÍAZ-CASTROVERDE LODEIRO, J.L.: El señorío de la casa de Sonán en su jurisdicción, gobierno y hacienda durante los siglos XVI al XX, Padrón, 1995; DOMÍNGUEZ CASTRO, L.: Viños, viñas e xentes do Ribeiro. Economia e patrimonio familiar, 1810-1952, Vigo, 1992; PRESEDO GARAZO, A.: Os devanceiros dos pazos. Economía e estratexias sociais da pequena fidalguia rural na Galicia interior (ss. XVIXVIII), Santiago, 1997; y VILLARES PAZ, R.: La propiedad de la tierra..., Op. cit.

${ }^{9}$ PRESEDO GARAZO, A.: Os devanceiros dos pazos..., Op. cit., pp. 17-24.

${ }^{10}$ GALLEGO DOMÍNGUEZ, O.: Manual de archivos familiares, Madrid, 1993, y "Os arquivos da nobreza e o seu tratamento arquivístico», en VV.AA.: Conserva-la memoria. Novas adquisicións da consellería de Cultura e Xuventude para o Arquivo do Reino de Galicia, A Coruña, 1993. También resultan de gran interés, en este sentido, las apreciaciones de FERNÁNDEZ I TRABAL, J.: «Els arxius familiars i patrimonials. Problemàtica, caracterizació i metodologia», Lligall, 4 (1991).
}

«CUADERNOS DE ESTUDIOS GALLEGOS», Tomo L, Fascículo 116, Santiago 2003. 
historiador debe acceder advertido por los evidentes inconvenientes que presentan estos completos y complejos fondo ${ }^{11}$. No obstante, no es nuestra intención hacer una relación pormenorizada de los mismos en el presente trabajo, por ser ésta una cuestión fácilmente salvable con la consulta de los diversos estudios citados a pie de página, y porque además merecería de un tratamiento más específico que rebasa con creces los límites de los objetivos iniciales que nos hemos propuesto ${ }^{12}$. Nos interesa tener en cuenta estos fondos documentales privados, ahora, en la medida en que la riqueza de contenidos que presentan referidos a las mentalidades y las actitudes de los individuos que habitaron en el pasado nuestros pazos rurales, raramente es superable a través de otras tipologías documentales. Y concretamente a un apartado temático, muy frecuente en los archivos nobiliarios, que ha suscitado un inusitado interés para el conocimiento de dichos aspectos señalados -mentalidades y actitudes individuales-, así como para el de la intimidad y la ideología: la correspondencia privada ${ }^{13}$.

${ }^{11}$ VILLARES PAZ, R.: «A agricultura galega no século XVIII. Fontes para o seu estudio», en VV.AA.: Fuentes para el estudio del siglo XVIII en Galicia. Historia económica y social, Sada, 1991, p. 21.

${ }^{12}$ Podemos señalar, brevemente, entre los obstáculos generales que presentan este tipo de fondos documentales, cinco que acostumbran a estar casi siempre presentes: $1^{\circ}$. No se conserva toda la documentación que se especifica en los inventarios documentales elaborados en los siglos XVIII y XIX, por lo que nos hallamos ante archivos parcialmente completos. $2^{\circ}$. La cronología documental de cada archivo no tiene por que coincidir con la que presente otro, por lo que siempre será preciso proceder a un análisis monográfico antes de estudiar las generalidades estamentales. $3^{\circ}$. La documentación administrativa acostumbra a aparecer a partir de mediados del siglo XVIII, por lo que hay ciertos aspectos relacionados con la administración hacendística cuyo conocimiento resulta complejo para antes de $1700.4^{\circ}$. Siempre se trata de fondos muy heterogéneos y dispares. Y $5^{\circ}$. en ocasiones no se conserva toda la documentación genealógica referida a la casa, por lo que es preciso acudir a otras fuentes -como los archivos parroquiales- para confeccionar las genealogías familiares.

${ }^{13}$ Sirvan como ejemplos representativos los siguientes trabajos en los que la correspondencia privada, junto con la documentación autobiográfica, aparecen como punto de partida para acometer la investigación histórica: GRASSI, M.-C.: «Un révélateur de l'éducation au XVIIIle siècle: expressions de la vie affective et correspondances intimes», Revue d'Histoire Moderne et Contemporaine, XXVIII (1981); D'AGAY, F.: «Les archives familiales d'Agay et la période révolutionnaire», La gazette des archives, 146-147 (1989); MENESES GARCÍA, E.: «Luis Hurtado de Mendoza (1489-1522)», Hispania, CILVIII (1976); MERRICK, J.: «The Family Politics of the Marquis de Bombelles», The Journal of Family History, 21-4 (1996); y TARRES, S.A.: «Memorias y diarios de la Cataluña Moderna», Historia Social, 2 (1988).

«CUADERNOS DE ESTUDIOS GALLEGOS», Tomo L, Fascículo 116, Santiago 2003. 
Entendida como «una conversation écrite, spontenée, familière, ou como un produit pensé et elaboré alliant la préciosité à la coquetterie épistolaire, elle a ses codes et ses lois» ${ }^{14}$, el estudio de la documentación epistolar ha abierto un interesante campo de investigación, en el que el individuo, y en un sentido más amplio la individualidad, han pasado a suponer un nuevo y sugerente punto de vista para el análisis del pasado histórico. Estos «ego-documentos» ${ }^{15}$, de los cuales también forman parte las memorias y los diarios personales, se pueden agrupar siguiendo el criterio de la afinidad temática en lo que S.A. Tarrés ha decidido llamar «literatura personal», es decir, aquella documentación histórica que «nos conduce directamente por los caminos interiores de los hombres pretéritos, pues, muchas veces, no solamente aporta datos y hechos, sino que también presenta interpretaciones y estados de ánimo imposibles de percibir en los documentos oficiales» ${ }^{16}$.

El documento histórico cuya transcripción literal presentamos a continuación, se circunscribe, precisamente, a dichas coordenadas archivística y temática. El Libro de cartas de correspondencia que tiene Blas Maria Rubiños fue compuesto por un hidalgo de la actual Mariña Lucense, que vivió en la segunda mitad del siglo XVIII y murió en 1814. Procede de un archivo familiar privado, el Archivo de la Casa de Mirapeixe (Rábade), y concretamente de la Sección Pardo Montenegro de Mondoñedo, en el que además existe una abundante riqueza documental referida a otras casas linajudas que asentaron sus solares en dicha comarca, así como en la Terra $\mathrm{Cha}^{17}$. Nos hallamos, luego, ante un individuo que, a tenor de nuestras pesquisas ${ }^{18}$, encaja a la perfección en el modelo de hidalguía que el

\footnotetext{
${ }^{14}$ GRASSI, M.-C.: art. cit., p. 174.

${ }^{15}$ Unas interesantes reflexiones en relación con estas fuentes en la recensión de SAAVEDRA FERNÁNDEZ, P.: "Anne Fillon, Louis Simon. Villageois de l'ancienne France», Obradoiro de Historia Moderna, 8 (1999), pp. 263-271.

${ }^{16}$ TARRES, S.A.: art. cit., p. 121.

${ }^{17}$ Para ser más exactos en el A.C.M.-P.M., leg. 39, mazo III. Queremos agradecer a Don Eduardo Pardo de Guevara y Valdés las facilidades que puso a nuestra disposición para consultar y catalogar en su integridad todos los fondos correspondientes a dicha sección del Archivo del Pazo de Mirapeixe. En total, dicha sección se halla compuesta por 55 legajos y siete cajas de documentación.

${ }^{18}$ PRESEDO GARAZO, A.: «Los ingresos económicos de un hidalgo gallego: rentas y negocios de Don Blas María de Rubiños (1772-1810)», Investigaciones Históricas, 19 (1999).
}

«CUADERNOS DE ESTUDIOS GALLEGOS», Tomo L, Fascículo 116, Santiago 2003. 
profesor Pegerto Saavedra definió en su día para el conjunto de dicha antigua provincia ${ }^{19}$. El origen histórico de la casa se remonta al último cuarto del siglo XVII, momento en que hemos localizado el matrimonio compuesto por Don Francisco González Maseda y Rubiños e Inés López Padriñán, bisabuelos de Don Blas María, y cuyo patrimonio vincular se consolida a partir de una serie de fundaciones vinculares que se suceden desde comienzos de la centuria dieciochesca hasta 1772, momento a partir del cual tanto el susodicho como su hermano, Don José Antonio Rubiños -asistente del obispo de Almería-, aparecen como los principales titulares del patrimonio familiar. Los escasos ingresos que percibe la casa anualmente en concepto de renta territorial -sin alcanzar los $25 \mathrm{Hls}$. de renta en especie líquida de media para el período 1772-1810-, sitúa a los Rubiños dentro del extenso sector nobiliario conocido como hidalguía humilde -muy difundido por todo el antiguo reino-, que pese a sus limitados ingresos disfrutaba, no obstante, de una nada desdeñable cota de poder a nivel local. Ello obliga, en parte, a que Don Blas ejerza de escribano de número en el concejo de Vilanova de Lourenzá, y que asimismo regente un ultramarinos en dicha villa coincidiendo con el momento en que se vive en el conjunto de la provincia mindoniense un auge de la protoindustria textil ${ }^{20}$. Finalmente, debido a su nutrida prole, compuesta por seis vástagos - dos varones y cuatro mujeres-, el principal cupo patrimonial le corresponderá a su hija Doña Josefa Antonia Rubiños (17881851), quien en su testamento beneficiará a su marido Don Lorenzo de Aenlle y Rocha, por lo que los antiguos bienes vinculares de los Rubiños se incorporarán finalmente a la Casa de Pividal -sita en el ayuntamiento de Trabada, en la frontera galaico-asturiana $-^{21}$.

El Libro de cartas de correspondencia es, pues, un libro en el que Don Blas María Rubiños ha ido anotando algunas de las cartas más singulares, y cuyo contenido era importante retener, entre 1790 -año en que presumiblemente accede a la escribanía de número de Lourenzá- y 1807, justo un año antes de que se produjese la defunción de su hermano Don

${ }^{19}$ SAAVEDRA FERNÁNDEZ, P.: Economía, Politica y Sociedad en Galicia: La provincia de Mondoñedo, 1480-1830, Madrid, 1985, pp. 567 y ss.

${ }^{20}$ Ibid., pp. 344 y ss.

${ }^{21}$ Ambas casas han sido objeto de estudio monográfico en nuestra tesis doctoral Dueños y señores de casas, torres y pazos..., Op. cit.

«CUADERNOS DE ESTUDIOS GALLEGOS», Tomo L, Fascículo 116, Santiago 2003. 
José Antonio en la ciudad de Granada, y de que, consecuentemente, regresase su hijo Don Vicente desde tierras andaluzas. Más allá de la destacada información que ofrece para el estudio del seguimiento procesual en las instancias judiciales en el Antiguo Régimen gallego, el libro nos presenta a Don Blas como un individuo de su tiempo que se vale del género epistolar para resolver desde Vilanova de Lourenzá cuestiones que se le plantean en ciudades tan distintas y lejanas como lo son A Coruña, Mondoñedo, Madrid, Getafe, Almería o Granada. Su singular concepción de cómo se han de entender las relaciones - de obligaciones y deberes- entre hombres de palabra que creen poseer honra, qué función debe cumplir el regalo u obsequio para afianzar las relaciones interpersonales en que es obvia la existencia de intereses mutuos, cómo ha de transcurrir la cotidianeidad en el seno de un hogar hidalgo, y sobre todo, qué papel desempeña cada quien dentro del complejo universo que supone la casa hidalga - cuya dinámica interna supedita a todos los miembros que la componen-; son, a no dudarlo, cuatro argumentos que justifican por sí solos la transcripción íntegra del documento histórico que presentamos a continuación.

\section{EL LIBRO DE CORRESPONDENCIA DE DON BLAS MA- RÍA RUBIÑOS: TRANSCRIPCIÓN ÍNTEGRA}

(Portada) Año de 1790.

Libro de cartas de correspondencia que tiene Blas Maria Rubiños, escribano de numero y ayuntamiento de Villanueva de Lorenzana.

(fol. 1r) Coruña.

Señor Don Josef Casal y Varela.

Mui señor mio de mi mayor esttimazion, sin enbargo del transcurso de tiempo que ha no nos hemos conttrattado por no haberse ofrezido, suzede en la ora y maiormente a lo /a/delante por allarme consttittuido escribano, uno de los del numero e insolidum del ayuntamiento de esta villa. Pareze que estte correo su merced el señor merino de la villa remitte a Vuestra Merced un testtimonio que le ha dado inttegro de los auttos obrados a pedimiento de Don Josef Pardo y Cordido, conbezino, sobre preferenzia en la venta del bino del pais a la de los Riberos, para con el informarse su 
excelencia y sobre de este real acuerdo como la tienen mandado por dos reales auttos a insttanzia de dicho Pardo, y attentto estte reuso la paga de los derechos como de el constta, y allarme descubiertto, y los de el prozeso, caso se dilatte la dizission de esos señores se sirba fazilittarme comision para la paga, pues el costte que tenga se lo remittire con el que cargue a dicho merino, y asi lo confio de su attenzion anttigua y el que me mande seguro de mi fiel affecto. Nuestro Señor guie y prospere su bida muchos años suia.

Villanueva de Lorenzana. Agosto 3 de 1790.

P.D.: La respuestta esttimare a Vuestra Merced me la remitta por el correo separada de la de el merino, y en todo de Vuestra merced astta $\tan [\mathrm{tto}]$ cumpla mi obligazion para con Vuestra Merced.//

(fol. 1v) En 19 de Agosto de 90 escribi a Don Joseph Antonio de Vega, de la Coruña, a su carta de 7 de Agosto de 90 sobre que le remiti 40 reales de los gastos alli, y 20 para el de gratificazion, que azen 60 reales remitidos a Don Ramon de Silva, procurador de Mondoñedo, como persona senalada para el depositto, en el particular de Francisco Antonio Loureiro y compañeros desta villa en ynstanzia de zapatos y curtido suszitada por Don Joseph Pardo.

Coruña.

Señor Don Josef Casal y Varela.

Mui señor mio de mi mayor esttimazion, recivi la de Vuestra Merced de 11 del corriente que agradezco por su correspondencia la que yo ofrezco en todo lo que pueda, sientto en el alma la faltta del pliego que inttroduxe el dia tres de estte mes con asisttenzia del merino en el correo de Mondoñedo, presente Don Raphael Lopez, esttafettero como lo demuesttra el testtimonio o firmas de dicho juez y mia que incluio a Vuestra Merced, e intterin se dan por aca los pasos debidos, zerca de ello esttimare a Vuestra merced se sirba dar qüenta a ese real acuerdo y señores para que dicho juez no esperimente daños y gasttos, pues los que se orixinen de esta classe con su abiso seran efecttibos en su pode[r], $\mathrm{y}$ en todo efecttuaremos quantto nos hordene para el maior aziertto. Que su mano besa.

Villanueva, Agosto 21 de 1790. //

«CUADERNOS DE ESTUDIOS GALLEGOS», Tomo L, Fascículo 116, Santiago 2003. 
(fol. 2r) Coruña.

Señor Don Francisco Anttonio Nabarro.

Somos nottiziosos los intteresados a la herencia de mi padre Don Lorenzo Rubinos, que goze Dios, que su biuda muger Doña Juana Folgueira y Cornide y su hijo señor Anttonio de Cora, inttenttan acabar de echar a perder no tan solamente la erencia de su difunto marido sino tambien la de su primera muger Doña Lorenza Gomez, mi madre y suegra respecttibe, con mottibo de asegurarsenos aber muertto el fiador que ha dado la Doña Juana como deposittaria de los vienes de dicho mi padre los herederos de aquel (que fue un hermano de la Doña Juana, llamado Don Josef Teixeiro) aseguran aora que todos los vienes que ha puestto en la fianza los tenia ya sujettos, o quieren apresenttar no llegan para las quiebras que ha dejado en el mayorazgo que poseiya, y para saliremos [sic] de estta duda se haze preciso el que Vuestra Merced a nombre nuestro solizitte real probission para efectto de zittar a los expresados erederos del Teixeiro si azettan o repudian la erencia de su padre y si tienen que pedir o repettir conttra dicha fianza lo executten denttro de um brebe termino que se les señale para luego que subzeda alguna cosa en conttrario poder repettir conttra la propia Doña Juana de nuebas fianzas, o en defectto se pongan dichos vienes deposittados en poder de persona desintteresada a la erencia como es debido. Vuestra Merced // (fol. 2v) lo sabe mejor que nosottros, abisando al mismo tiempo de su costte, como tambien de ottra alguna cosa que obcurra. Que es lo que por aora se ofreze a estte su seguro serbidor. Que su mano besa.

Blas Maria Rubiños. Villanueva, septiembre 4 de 1790.

P.D.: Serbirase Vuestra Merced conttesttar a Mondoñedo bajo cubiertta para mi cuñado Don Lorenzo de Riba y Ottero poniendo los gasttos separados de ottros que estte pueda tener.

Coruña.

Sobrino y amigo, doy respuesta a la tuia por no poder executtarlo anttes de aora, por lo que te doy las debidas grazias por el cuidado que has tenido quanto al asumptto de mi amigo Pardillo, lo que nuebamente te encargo que de qualquier prettension que aga por medio de tu amo me habises sin perdida de correo. Aora nuebamente te ago encargo que conttiene el poder adjuntto que te remitto que espuso mi ofizial y lo ha dado a signar al escribano mi vezino por allarme a la sazon ausentte que 
fue mottibo el dilatar la respuesta, esttimare lo to//mes (fol. 3r) a tu cuidado como cosa propia, pues me instta el serbir a los vezinos de mi jurisdiccion y el que quanto anttes puedas me remittas el despacho que por medio de el se solisitta abisandome de todo el despacho que tenga, como tambien del portte de las carttas del correo pues no es justto se te harrime al bolsillo, que todo lo que fuese con tu abiso pondere [sic] en la persona que señalares. Es quanto por aora obcurre y manda a estte tu afectuoso tio que desea servirtte.

Villanueva, octubre 3 de 1790. Blas Maria Rubiños.

Sobrino Don Josef Anttonio de Vega remittio la probission con fecha 9 de octubre de 890 . Su costte 43 reales vellon que enttregue a Don Ramon de Silba en 19 de dicho mes y año.

Coruña.

A fabor de los de Azebro.

Villanuena, septimebre 13 de 1790.

Sobrino, a tiempo que he llegado de afuera de unas parttixas a estta tuia recivi 3 tuias, la primera de abertte abisado tu tio Silba se hallaban en su poder los 43 reales que se te adeudaban de el despacho que has remittido a fabor de los vezinos de el Azebo y las ottras dos consecuttibas, la una que en todabia no habian parezido los vezinos de que el procurador $\mathrm{Ba}-$ rros ya tenia presenttado poder y pedio bistta de auttos, y asi luego // (fol.3v) que se te de traslado me remittiras lo alegado por las conttrarias y para su conttradizion y que puedas adelanttar alguna cosa mas, te remitto el propio papel que oy dia se me enttrego para que de el saques lo faborable para conseguir el buen exsitto que espero lo executes, que quanto a lo mas no tengas cuidado que yo are que la grattificazion sea gusttosa (no perdiendo dicho papel pues no tengo ottro seguro astta aora) el que me lo bolberas a la primera que me escribas. Es lo que por aora se ofreze a bisitarte y manda a estte tu affectuoso tio. Que tu mano besa.

Rubiños.

Coruña, noviembre 20 de 1790.

Sobrino y amigo, recivi la tuia con los ynserttos que le acompañaban, y echo cargo de uno y otro digo que sobre el conozimiento de la causa estribara sea la justizia real del Valle de Lorenzana donde ay escribano de

«CUADERNOS DE ESTUDIOS GALLEGOS», Tomo L, Fascículo 116, Santiago 2003. 
numero, confinante y pegado a los terminos de las contrarias, pues suzede pruevas y vistas oculares se azen a menos coste, pues em Mondoñedo con la sobrante leña que tienen ganaran las boluntades contra la justizia que asiste a los nuestros, espero no descuides [y anotar] que are se aga efecto. Ynterin a Dios que te conserbe, que asi lo desea tu tio que besa tu mano.

Rubiños. //

(fol. 4r) Coruña, deziembre 18 de 1790.

Don Josef Bega.

Sobrino, doy respuestta a dos tuias, una de fecha de $1^{\circ}$ del que corre y ottra de 16 del mesmo, lo que no pude executtar astta oy dia por allarme ausentte de estta en cosas perttenecientes a mi ofizio, y te doy las debidas grazias por el mucho cuidado que astta aqui has tenido con la dependencia que te encargue quanto a los vezinos de el Azebo, pero se haze tambien preziso me enbies a dezir que dinero nezesittas aora al pronto para con tu abiso remittirttelo sin perdida de tiempo, pues no es razon esttes supliendo inttereses algunos como lo ejecuttas, y si gusttas inbiaras la qüenta para azer se me aprontten e io executtarlo a ti con el papel que te derixi con cartta 13 de noviembre de estte año en la que te exponian no perdieses dicho papel y me lo remittieses a bueltta de correo, pues astta aora que no tenia otro seguro. Abisame tambien (estto es de tio a sobrino) si nezesittas para alguna merienda de esttos dias de fiesttas y de puntto alguna friolera de zezina o perniles para ablarles me lo conduzcan tambien, que estto [s]aliendo com[o es]peramos en Dios con buen exsitto no impide el que despues se expliquen con la grattificazion de dinero que bien conozco lo esttiman mas en esa los ofizios de plu//ma (fol. 4v) que ottra cosa alguna de Pasquas. No te digo nada sino que las logres con todo regozijo y aumento de grazias.

\section{Coruña.}

A su señoria el señor fiscal de lo zibil.

Señor, como su seguro servidor digo a Vuestra Señoria que en $1^{\circ}$ del que rixe, asisttido del escribano de ayuntamiento se zelebro la juntta que Vuestra Señoria se dignara reconozer, y por la disformidad de elecciones de ofizios que han nombrado los bocales a vistta de lo mandado por la subperioridad, y que llegue a conozer mottibado de las reales hordenes 
que mande rexisttrase al zittado escribano con los mottibos berdaderos que tengo de obserbarlas y la buena admenisttarzion de justticia, por lo mismo me fue preziso hazer segunda juntta como en ellas se prebiene, y no siendo al gustto el escribano de numero Vernardo Valledor por no salir a su inttento como lo prettende segun lo demuesttra lo obrado, pettizion presentada por estte y relazion de su conclusion, me hes preziso hazerlo presente a Vuestra Señoria para que se digne dar qüenta a su excelencia y señores de ese Real Tribunal y en su bistta mandarme lo que fuere de su maior agrado con la pronttittud que aclama el inttentto dandome Vuestra Señoria anttes nottizia de aber llegado // (fol. 5r) estta y testtimonio a sus manos para mi inttelixencia.

Villanueva, enero 15 de 1791. Beso su mano de Vuestra Señoria, su mendador Juan Anttonio Hermida.

Coruña.

En dicho dia eschribi a Don Josef Bega me exponga que dinero quiere que ponga en poder de su tio Silba para el caso de los Azebo que con su abiso se le enttregara.

Enero 15 de 1791.

Villanueva, febrero 4 de 1791.

Señor Don Phelipe Caveza Castañon.

Valladolid.

Dueño y señor, por mis ocupaziones y aberseme muerto mi parienta, que goze de Dios, no pude hasta oi dia dar respuesta a la mui favorezida de Vuestra merced, su fecha 7 de diziembre del año retroprosimo pasado, agolo aora diziendo en primer lugar remito a Vuestra merced las dos reales probisiones con sus delixencias echas y practicadas al asunto segun se sirvira reconocerlas, pues allo mucha controbersia en ellas, motivado del escribano que ha dado fee y perder el uno y costunbre del probervio antiguo de la patria, admas de la equibocazion que [es] de primera a segunda muger como lo demuestran las delixencias pr[a]cticadas, y para maior claridad yncluio el arbol que de sus notas conozera Vuestra Merced con claridad, lo resultante // (fol. 5v) de las prendas ynsertas en el prozeso, que mire en la madurez que acostumbra pidiendo en su birtud lo que alle combeniente a toda equidad, y si fuere nezesario alguna prueva de testigos para la mutazion de Cavallero a

«CUADERNOS DE ESTUDIOS GALLEGOS», Tomo L, Fascículo 116, Santiago 2003. 
Cavaleiro, $u$ otra alguna mas zircunstanzia, me abise sin perdida de tiempo. E ynterin, siempre de Vuestra merced, este su amigo que su mano besa. Rosendo Fernandez Cavaleiro.

Coruña, fevrero 12 de 1791.

A Don Josef Vega.

Sobrino, doy respuesta a dos tuias, una de fecha 29 de enero prosimo pasado por la que me aseguras que dabas para articular en la prueba que deben dar los vezinos de el Azebro por quienes hazes lo que te estimare despaches quanto antes puedas, motibo de que me han asegurado no poder este año cultibar monte alguno por no tener con quien zerrarlo, y quieren dar quanto antes la prueba. En quanto al relator, se tiene dependencia para Mondoñedo Juan Cordido, ofizial que ha sido de el relator Herbella, si es que se pudiera entregarle la probanza, los estimara, pero como estos caballeros tienen turno sera a quien le tocare a menos que se baliesen de el ofizial maior de el ofizio que a bezes tambien se entregan.

$Y$ en quanto a encaminarle en derechura al Azebro y casa de Antonio Diaz, que alli no le faltara todo lo que zita tu carta, y si es que quiera benir por Mondoñedo abisandome el dia que llege [sic] le hire a buscar, y desde esta hiremos juntos asta yntroduzirlo en casa de el Diaz y dexarle en el auditorio comodo que se nombre. A la otra de fecha 5 del corriente digo no te falta razon a lo que en ella expones, pero tambien es preziso te baxes a refleusionar no poder tiempo como te aseguro a ley de amigo para comer muchas bezes como me subzedio estos tiempos por dibersas bezes // (fol. 6r) el uno por tanto como me da que hazer el ayuntamiento que mas me baliera no tenerlo (y ser solo escribano numerario) con tantas hordenes como a cada paso estan llegando, otras de el numero de la Santa Mision que ay en el pueblo, y por ultimo otra dependenzia que me entregaro [sic] de ese Real Tribunal y de la sala de el crimen contra la justizia de Trabada, que esta fue la que pidio en el pronto mas motibo para no poderte escribir asta aora por andarseme escapando el juez y no poder cojerlo para dilexenziarlo, y como no llegase a esta fecha 19 de enero ya zitado, solo tube lugar de despachar a tu primo Pepe con los 140 reales para que se los llebase a Don Ramon de Silba, y te eschribiese de averlos recibido asta que yo lo pudiese executar.

Pero en quanto a lo mas que ella expresa no tienes que pensar tan lixero de mi, y el motibo de no haberse un hombre mostrado agradezido 
fue de los conductores que ay en la ya zitada de Mondoñedo para esa aberse marchado despues de tenerle abisado tenia un enredo que remitir para alla.

En fin, esta dispuesto para ti y para otro amigo mio que es el secretario de el real acuerdo Don Josef Casal y Varela, y no se presentando conductor antes de brebes dias are propio para que llege [sic] antes de Carnestolendas. Abisa de qualquiera cosa que se te ofrezca y manda a este tu affectuoso tio seguro serbidor que tu mano besa. Rubiños. Sobrino Don Josef Antonio de Vega.//

(fol. 6v) Coruña.

A Don Josef Casal y Varela.

Dueño y mui señor mio, por Luis «el lenzero», trattantte en esa, remitto a Vuestra merced una pierna de baca zezinada aconpañada de dos perniles, uno y ottro para ayuda de dos pucheros de los domesticos de esa mui suia. Sirbiendose desimular la corttedad astta mejor ocasion y mandar en lo que conttenple pueda serbirlo, estte su affectuoso seguro serbidor y amigo que su mano besa.

Villanueva, fevrero 26 de 91. Blas Maria Rubiños.

\section{Coruña.}

Don Josef Anttonio de Bega.

Amigo, oy dia por mano de tu primo Pepe recivi la tuia su fecha 16 del corriente, y a su conttestto debo dezirtte que pocas o ninguna bezes te pondre responder a buelta de correo, mottibo que ya tengo mui anttes de aora explicado, y admas las partes que defiendes esttar desbiados de estta tuia tres leguas y no llegar el dia, a bezes para hir y benir al propio. En fin, el dictamen que quieres te remita copia esta en poder de ellos, are por que benga a mis manos y de sacada te la remittire sin perder tiempo y me agan presente. Por Luis «el lenzero» // (fol. 7r) te remitto dos perniles y tres buelttas de longaniza para esttos dias de Carnesttolendas puedas echar mas un trago, y por no duplicar carttas diras a nuestra Marica que su prima y tu tia Doña Josefa Moscoso le remitte por el mismo una libra de zierros olandeses del lino que se gastta en casa, y una bexiga de mantteca para las sopas de dos mañanas, perdonando uno y ottro la corttedad astta mexor ocasion. Remitto la copia que me pides que a toda priesa mande buscar por propio seguro su orixinal para aber de sacarla, y me abisan no

«CUADERNOS DE ESTUDIOS GALLEGOS», Tomo L, Fascículo 116, Santiago 2003. 
tienen que adberttir ni adelanttar mas nada para el artticulado, solo que la $4^{\mathrm{a}}$ preguntta les pareze no podran acredicttar lo que ella conttiene, y en quanto a lo mas todo lo que zitta el dicttamen y asi mejor sera dexarla fuera, es lo que obcure [sic] y manda a estte tu seguro serbidor. Rubiños.

Villanueva, fevrero 26 de 91.

\section{Madrid.}

Don Domingo Anttonio Varela.

Dueño y mui señor mio, despues de apettezer nottizias de su salud, prima y sobrina Doña Ysabel sirbe estta hazer presente a Vuestra merced el haber enttregado oy dia al maragato Anjel Fuerttes, vezino de el lugar de Quinttanilla, para que condud//ca (fol. 7v) a poder de Vuestra merced una pierna de baca trasera zezinada, un par de perniles y dos lenguas, todo curado para ayuda de dos pucheros sirbiendose abisarme para mi gobierno de su enttrega, el portte ba pago como zitta la que lleba.

Sirbase ponernos a la obediencia de las dos referidas con expresiones de nuestra parte y mandarnos en lo que conttenplen puedamos serbirles, de estta suia y suio, que su mano besa.

Villanueva, fevrero 23 de 91 . Por no tener respuesta le escribi en 23 de abril para que me habisase de el recivo de la anttezedente.

\section{Coruña.}

Villanueva, 5 de marzo de 1791.

Sobrino, recivi la tuia con el dictamen y mas que expresa fecha 2 de el que rixe, y leido el ofrecimiento de la $4^{\text {a }}$ pregunta me admiro bastante por los ofrezimientos que de mis recomendados pueden ocurrirles, y asi dando de mano a nuestro deseo escrivi e yze propio desde esta tuia y distanzia 2 leguas para que me contestasen lo claro de lo que se podia verificar, y se me contesto lo que consta de la carta que yncluio de la que sacaras a la $4^{\mathrm{a}}$ pregunta lo luzido que la corresponda en su articulado, pues esta jente no se rinden ni flaquean por ser la resistenzia contraria mas que ympia a conseqüenzia de dicha carta y mas expuesto, por lo que estimare como hasta aqui la biveza con aviso de todo.

El ymporte de la carta quarta sera efectiva donde dizes y mas que digas, ynterin manda a este seguro y fiel tio que te desea y mano besa.

Amigo Don Joseph Antonio Vega. // 
(fol. 8r) Coruña.

Villanueva, marzo 22 de 1791.

Sobrino, estta bien artticules inmediattamente para la prueba de los vezinos del Azebro sin discuidartte en ello pidiendo recobracion de sattisfazion como promettes, abisandome el dia que podra llegar a Mondoñedo para esttar propio que le conduzca, al propio lugar del Azebro, y siendo el inttermedio se ofreziese algun partticular o nobedad me lo anunpziaras que es lo que por aora obcurre, y manda a estte.

Sobrino Don Josef Anttonio de Vega.

Coruña.

Villanueva, marzo 22 de 1791.

Señor Don Josef Casal y Barela.

Se le respondio a su cartta de fecha 16 del corriente mes y año diziendo que el cargo de salmon siempre que subzeda aberlo para la Semana Santa se le remitta, pero por ser tan altta lo pongo en duda y aber poca fructta de el xenero, y abiendolo anttes de dicho tiempo si se le remittira o no. Y en el intterin y siempre, puede mandar en todo lo que se ofrezca.

Respuesta al ajente de La Coruña.

Recivi la tuia, su fecha 26 de pasado, acompañada del ynterrogatorio de preguntas echo a favor de los vezinos del Azebo, por que te di las devidas grazias abisandome a tiempo el dia que sale de esa el rezetor y si biene en derechura para aquella del Azebo o si tiene otro destino // (fol. 8v) antes de esta en que dia podera llegar a Mondoñedo o a aquella, y en el ynterin manda en lo que se te ofrezca a este tuio que tu mano besa.

Abril $1^{\circ}$ de 91.

\section{Coruña.}

Señor Don Joseph Antonio de Vega.

Amigo y sobrino, a la tuia de 3 del que rixe digo que el articulado me parezio bien, y de venido el rezetor se le entregara para nuestra prueva, si hes que la rezetoria no este despachada y entregada lo suspenderas hasta que llegue a esa Don Juan Cordido, rezetor mi amigo (que deseo venga), que luego me dijo se retiraba a los asuntos que trahia. Tener cuidado y abisarme de lo que ocurra. Y adios y manda a este tuio que tu mano besa.

Villanueva, abril 9 de 791.

«CUADERNOS DE ESTUDIOS GALLEGOS», Tomo L, Fascículo 116, Santiago 2003. 
Para La Coruña.

Abril 19 de 1791, Villanueva.

Sobrino, recivi la tuia allandome en la ciudad de Mondoñedo, su fecha 12 del corriente, y sientto mucho dartte la respuesta que te boy a dar, pero me da mottibo el juzgares tan lixero de mi prozeder. Como anttes de aora te tengo dicho que te basttaba si lo tubieras presente, y como no lo tienes y en esa te benttilan los ayres de la mar, me presumo sera el mottibo zittado que ottra cosa no lo attribuio ni pienso me pase por la maxinazion. En el propio correo y con fecha 16 de el de arriba expresado eschribe Barros, procurador de las conttrarias, diziendo les remitte copia de lo que ha artticulado, y tan prontto se cargue, receptor les abisara. Con//ttempla (fol. 9r) tu las fechas y lo eschritto de parte a parte, y en estte asumptto no te digo mas (que a buenos enttendedores pocas razones). Basttantte me dio que pensar los dos artticulados que me has remittido, uno despues de el ottro, en que no hize tantto altto como aora me aze suxetar. En fin, si quieres seguir como yo he presumido lo executtases, no perderas nada que admas de tu axenzia ya tengo dicho mi senttir, y en defectto con tu abiso hare se pague lo que se deba $\mathrm{y}$ despues me pondre peor o mejor que anttes que fueses para esa, ya se como se corren los bolos, que aunque no lo supiera tantto alguna cosa mas tenderia. Por ulttimo, para que bengas en conozimiento de si sale de mi capricho lo que te adbiertto es te remitto un tantto de lo artticulado por dicho Barros que cojieron nuestras partes aconpañada de la cartta que he lehido, y no quisiera que la presumpzion que han echo de mi (sin saber malditta la cosa) la hubieran echo por 50 doblones, que bale mas mi creditto y pundonor que quanto dinero aiga, y ottro tantto hara qualesquiera que tenga pudor en su cara. Tambien me advirttieron y llegaron aberiguar que el abogado que tienen (sin animo de injuria) no es de los que han inbenttado la polbera, pues pareze ya esttubo un largo tiempo suspenso en el ofizio y tantto le lleben tantto firma a hojos zerrados, por lo que sera preziso mudarse a ottro. Espero respuesta para dar sattisfazion y que todos quedemos con buena fama y opinion como quiera Dios lo permitta, a quien pido guarde tu bida muchos años, que te estima tu tio Rubiños.

Sobrino Don Josef Anttonio de Bega. // 
(fol. 9v) Para La Coruña.

Villanueva, maio 20 de 1791.

Sobrino y amigo, salud y grazia, saberas de como nuestro amigo Don Josef Alfeiran, receptor hordinario, nuestra probanza en la que ban conformes 6 testigos, para domingo que $1^{\circ}$ biene se prenzipia la prueba conttraria, y asi pedir despacho conpulsorio de el apeo que se hizo para el Real Monasterio de estta vila de lo pertteneziente al cotto del Azebro que prezedio el año de mill quinientos treinta y siette a testtimonio de Fernan Sordo, y asi no discuidar la remesa del despacho, para ello que con la pronttittud puede se aorren maiores gasttos zittando y enplazando luego que lo rezibas al procurador conttrario Don Anttonio Barros, que aunque estte de por parte a las suias, ni por eso se les haze alguna delixencia despues, segun expuso el Don Josef Alfeiran. De lo mas que obcurra te abisare, e interin soy tuio y manda a este tu affectuoso tio que tu mano besa. Rubiños.

Sobrino Don Josef Anttonio Bega.

Notta: el apeo que ba zittado para en el archibo del Real Monastterio y se ha de delixenciar al Reverendisimo Padre Abad para que de lizenzia para abrirle, reconozer y sacar dicho conpulsorio. //

(fol. 10r) Coruña, Junio 20 de 91.

A Don Josef Anttonio de Bega.

Sobrino, por el dador te remitto este testtimonio con el poder adjuntto que reconozeras mui por menor a efectto de hazer el pedimiento para conseguir lo conduzente para un buen exsitto y que de frusttado lo que quiere operar el merino y mi compañero Valledor, pues segun soy nottizioso marcharon oy de estta villa ha ir rezibir la probanza de su inttentto sin horden ni forma de derecho, pues semejantte practtica nunca la he oydo ni bistto, discurro que dicho Valledor como directtor de todo quiere poner en estta villa practtica nueba. Te remitto 50 reales para el giro de estto abisandome de su costte para mi gobierno. En el dia 10 de Junio del corriente año enttregue al receptor Don Josef Alfeiran 200 reales para que estte lo hiziese a ti con cartta que les aconpañaba de que asta aora no tube nottizia. Que tu mano besa.

Si es que aiga mucha dettenzion despacha el propio abisandome por cartta mano de estte es para Felix Lozano.

Se estta trabajando en el cunpulsorio a toda prisa para remettirte, que te sirba de adberttencia. //

«CUADERNOS DE ESTUDIOS GALLEGOS», Tomo L, Fascículo 116, Santiago 2003. 
(fol. 10v) Coruña, 28 de Junio de 1791.

Para Felix Lozano.

Sobrino, ayer dia recivi la tuia aconpañada de el despacho adjunto de mi recomendado Felix Lozano, y luego que no hize mas que perzivirlo contesto y allarse mui cerca de mi tu tio Don Ramon de Silva, pase en continente a entregarle los treinta y tres reales y ocho maravedis que zitava los propios que se hallan gorismados [sic] en dicho despacho, lo que es mui regular te abise es aunque es cierto me expresa no lo aria asta el siguiente correo y que el despacho, digo deposito, que tienes en su poder ba creciendo, de el recivo quando te avise me lo comunicaras para mi govierno lo propio que executo. Que besa tu mano.

Coruña, 2 de Julio de 1791.

Sobrino y amigo, por el adjuntto testtimonio y delixencias practticadas a conttinuazion de la probission que me as remittido de que ya tengo dado sattisfazion, reconozeras lo obrado por parte de Felix Lozano y el ningun cumplimiento del merino a lo justtamente mandado por esos señores dimanado de los influxos de Valledor y ottros, por lo qual te encargo esttes a la bista por si las conttrarias fomentan con sus tramoias al//gun (fol. 11r) recurso, lo que conttradeziras en birttud de el poder, y considerando preziso nueba representtazion, con presenttazion de los papeles adjunttos conttra dicho merino la aras y consiguiras despacho faborable que el costte que digas sera efecttibo. Con estta ocasion siempre tuyo, que tu mano besa.

Sin enbargo de que te adbertti en la anttezedente yba Balledor de adjuntto con el merino Azillero a rezibir la informazion segun lo hizieron por antte Francisco Martinez, escribano de el numero de el calendario de San Cosme de Barreiros, no hizistte expression de estto, y en el dia conduze esforzar estte puntto mediante no me enttregaron la causa de que soy orixinario y me conpette en birttud de la real probision por Felix Lozano, por lo que se conoze una pura coligazion y progreso regular de la causa a que quando ba el señor Don Jil Sanchez, abogado asalareado del monasterio de estta villa, por los respecttos de complazer a los reos por medio de el padre provisor de dicho monastterio, por ser el Josef Garzia de Prado y su muger caseros suios y aber serbido en el de criados astta que se casaron, y la muger en la casa y horno de los molinos, por cuias fuerzas superiores no puede el Felix vindicar su honor, pues no ha//biendo (fol. 11v) manifesttado coneusion alguna conmigo, no tenian mottibo ni dere- 
cho para que el merino se aconpañase de escribano de afuera de la jurisdiccion esttandole proibido por reales hordenes qual no quisiere y obrar con adjuntto, porque en estte caso debia recurrir para mejor aziertto y gobierno de la adjudicattura a Real Tribunal, como lo hizo el Felix.

\section{Coruña.}

Villanuena de Lorenzana, Julio 12 de 1791.

Sobrino, doi respuesta a la tuia, su fecha 6 del corriente, aconpañada de la provision adjunta de Felix Lozano, su ynporte 31 reales, que remitire en la hora a nuestro pariente Silva, cuio pleitto para que era su benida tranquilo su Señoria Ilustrusima el obispo de Mondoñedo, allandose en esta aziendo visitta.

Adjunto a esta remito el conpulsorio sacado del archivo del real monasterio de esta villa a nombre de los vezinos del Azebro, por quien hazes, el que reconozeras con todo cuidado abisandome de lo que aiga de nuevo con advertenzia que el de los contrarios no se trabajo todabia nada en el.

En quanto a abogado se dexa a tu disposizion, pues bien conozes la defensa y bozes que nezesitta el que defienda, tambien te ago presente me abises si hes combeniente sacar conpulsorio de la carta de poblazion y foro que el monasterio desta villa hizo en la hera de 1327 que hes año de 1289 a 15 pobladores para que poblasen el monte de Monfrixie, que hoi dia llaman del Azebro, que paso ante Juan Perez, notario publico vezino que fue desta nominada villa, cuio ofizio tambien se alla en el archivo de dicho // (fol. 12r) monasterio, y dentro de las testadas que contiene se alla el monte y fraga de la disputa perteneziente al ya zittado de Monfrixide que hoi es el coto que nominan del Azebro, consultaras esto antes de presentar el ya zitado que remito, y allandolo ser combeniente me remitiras nueva provision para ello a efecto de sacarlo y presentarlos juntos. Hes lo que por aora se ofreze, y en lo que ocurra abisa a este tu afecttuoso que tu mano besa.

Coruña.

Copia de la carta escrita a Don Blas Maria Ramos.

Villanueba y Agosto 28 de 1795.

Ahijado, ahi te remito este poder a efecto de que tomes a tu cuydado ese negocio lo propio que si fuera cosa mia o tuya que todo lo que se ymporte, admas de tu ajencia a donde quieras que se te ponga con tu aviso

«CUADERNOS DE ESTUDIOS GALLEGOS», Tomo L, Fascículo 116, Santiago 2003. 
en la hora sin la mas lebe detenzion se hara. Hazte cargo de el y si por acaso llegasen los autos al oficio que corresponde, que no te puedo decir qual es por las picardias con que usa mi companero, podras presentarlo y hacer correr el rumbo a que aspira, y en defecto que no lleguen a esa suspendras [sic] su giro hasta segundo aviso, bien entendido que el poder contrario creo es Couto, que te sirba de abiso. Quiere la parte contraria y pretende composicion, y pidio suspension por unos quatro $\mathrm{u}$ ocho dias, pero yo como se con quien se juega no me fundo, pues el citado mi companero no es de los mas // (fol. 12v) sanos para estas cosas, que si puede hacerla la usa y no se discuyda, pero con tu favor y de otros amigos hasta ahora a Dios gracias no las ha logrado conmigo, y por lo mismo siempre es bien andar adelantado y con tal que se presenten en este tribunal tambien yo tengo que salir al pleyto como lo podras reconocer, siempre que llegue a tus manos avisame del recibo y manda en lo que te pueda serbir a estte tu affectuoso padrino que bien te desea. Blas Maria Rubiños. Ahijado Blas Maria Ramos.

\section{Coruña.}

Villanueva, Septiembre 5 de 1795.

Haijado, tendras presente que la conposizion que te dije en la antterior a estta no es ninguna, por lo que la parte contaria mando dezir a Balledor no remittiese los auttos por el correo, pues los a de llebar por su mano propia, y asi esttaras hojo alertta sin pedir despacho alguno para que baian orixinales, y luego que lleguen ad lo debido, con adverttenzia que la inttenzion del amigo por quien me hallo intteresado no es mas que salir con la suia y con honor, al gasttar no tiembles tantto en regalos como en propinas pues se deja a mi arbittrio, e io lo dejo al tuio, abisandome en tiempo del dinero que nezesi//ttes (fol. 13r) pues en esa no sirben ottros regalos, como estoy bien sabedor de todo ello tambien se halla intteresado el padre procurador de la Relixion Bernarda por parte de dicha conttraria, pero lo que mas me alientta a mi para salir con todo garbo en el ser la primera benta de vienes que a echo el bendedor marcada de la zittada conttraria y con zittazion haber tomado posession de ellos el zittado mi amigo por quien me hallo intteresado, que es la mejor que tiene por el casttillo de forttaleza para su defensa. Esttaba para salir para esa e hir a dartte una besitta de mi parte y lo mas que se agrega, pero como la copia de auttos aun subsistte en estta era el hir adeboluttum, como suelen dezir, 
como no ignoras le pribe el que lo executtase por el motibo de que en el partticular no azia nada, y asi en un todo lo deja el, e io a tu cuidado. Y en lo que se ofreziere abisarme al insttantte por el correo sin perder tiempo alguno, pues el Juan Fernandez estta de marcha para Casttilla a las cobranzas de el lienzo que le esttan adeudando y compra de el lino de aquel pais, y se teme que en estte inttermedio se le aga alguna traizion o picardia, que todo ello tendras presente con lo mas que se obcurra habisandome tambien del recivo de estta y mas manda a este tu affectuoso padrino que te esttima. Rubiños. Haijado Don Blas Maria Ramos. //

(fol. 13v) El sobreeschritto de esttas carttas se pone a Don Blas Maria Ramos, nottario casttrense y ofizial maior de la escribania de renttas reales y ajenzia fiscal del crimen de la Real Audiencia de estte Reino en Coruña.

Coruña, a Don Blas Maria Ramos.

Villanueba, Octubre 3 de 1795.

Ahijado, doi respuesta a la tuya de fecha 15 de septiembre pasado de este corriente año, y por ella reconozco la equivocacion que as padecido en escrivirme anticipado, supuesto no he echo la entrega de los trescientos y veinte reales que en ella citas a tu ermano asta el dia 22 del mismo mes de septiembre, de que te daria aviso juntamente con la que yo te e remitido, esto te lo digo para que te reconoscas que aunque estas en la fuente a veces se suele caer en un charco, acuerdate de otra que me has escrito no a muchos meses.

Adjunto te remito ese otro poder para que por el solicites la real provision que se pretende y de echo sin detencion alguna me la remitas avisandome de su inporte, que are efeutivo en la ora. Que te estima tu padrino Rubiños. //

(fol. 14r) Coruña, a Don Juan Lopez Leitton.

Marzo 22 de 96.

Amigo Don Juan, por mano de su cuñada, muxer de su hermano Fernando, recibi de horden de Vuestra Merced media arroba de bacalao con que Vuestra merced se sirbio faborezernos, por lo que doy a Vuestra merced las mas debidas y atentas grazias pues no habia merito por mi para tanto fabor.

«CUADERNOS DE ESTUDIOS GALLEGOS», Tomo L, Fascículo 116, Santiago 2003. 
Dicho su hermano Fernando me apura mucho a fin de que haga saber a los colognos y llebadores de las piezas de heredad sueltas que no son de foro les haga saber nombren su perito yntelixente a fin de que junto con el que elixiere reconozcan las tieras y tasen lo que deben pagar aquellos anualmente a Vuestra merced, lo que no puedo executar por no tener facultades en la real probision para ello, pues esto se ha quedado en el tintero a su procurador el pedirlo, y solo lo hizo de la posesion, y que se hiziese saber a los auctuales colognos y llebadores que desde el dia de la notificacion hagan y tengan por lexitimo dueño de la azienda que comprende la escritura de foro a Vuestra merced mismo, y concurran a combenirse (delante) sobre lo que subcesivamente deban pagarle, y a recibir nuebos arriendos, segun asi se ha mandado, y que se yntimase el desaucio a los colognos y llebadores de la feligresia // (fol. 14v) de Masma y Villamor, lo que no se puede executar hasta el mes de enero primero que biene de nobenta y siete segun lo contiene la horden comunicada al asumpto, pues los desaucios solo se puden hazer tanto el caso como el amo por dicho mes de cada año y no en otro.

Yo no puedo andar mas lijero aunque quiera, pues si lo pudiera hazer todo en un dia o dos hera mi gusto, pero no se acomoda, como el trato es con tan buena jente e ynducidos de aquel buen sujeto de Blas Perez y su hijo, como todo ello le consta a su hermano Fernando.

Vuestra merced no se discuide en librar la probision en los modos que le tengo insignuado por la anterior a esta, y en ella tambien pedir lo que falto en esta otra, que es el que los llebadores y colognos de dichas piezas, fuera los de Masma y Villamor, siempre y quando quieran subsistir en la llebanza de ellos a la orden nombren su perito yntelixente que junto con el que por Vuesta merced fuere elixido tasen lo que deban pagar, y no siendo conformes que el executor lo nombre de ofizio, y accetando la tasa den la fianza suficiente para estar seguro la paga de lo que deban de hazer annualmente cada uno de ellos. De este modo bino otra real probision para el monasterio de esta villa, la que he echo saber a algu//nos (fol. 15r) caseros y colognos de el lo que asi se debe executar, con la que remito pues la que tengo aca solo me las da para lo que llebo espuesto que es lo que nuebamente tengo que dezir a Vuestra merced. E ynterin y siempre mande a este su affectuoso y seguro serbidor que su mano besa. Blas Maria Rubiños. Señor Don Juan Lopez Leyton. 
Villanueva de Lorenzana.

Almeria, Marzo 27 de 97.

Hermano, despues de (apettezer) digo deseartte perfectta salud, sirbe estta de enumpziartte aberse falleszido al amanezer el dia 23 de estte corriente mes y año a las tres de su mañana su Señoria Yllustrisima el Yllustrisimo Señor Don Francisco Quadrillero y Mota, Obbisppo y señor que fue de la ciudad de Mondoñedo y su obbisppado, no puedo explicartte en estte partticular ottra cosa alguna por no ser sabedor de mas nobedad.

Te ago presente haber enttregado en el dia de ayer al maragato Marcos de Ottero el lienzo de tu encargo, pero no lleba la tela // (fol. 15v) mas que 45 varas, falttandole al conpletto de tu encargo cinco baras, es la mas blanca y fina y toda echa de lienzo gallego que luego que baia al agua se pondra como una tabla, ban en el medio de ella treze pares de calzettas enttre las que ban dos pares echas por mano de tus sobrinas Pepa y Marica, tambien de hilo gallego, no ban tan blancas como las ottras por no haber llebado despues de echas mas que tan solamente dos coladas, pero ya se blanquearan, y me pareze seran las que an de durar mas, lleban por señal las de Pepa al prinzipio y al altto una borla de seda verde y encarnada, y las de Marica azul y encarnada, te suplican las pongas quanto anttes puedas y les mandes dezir tambien si te bienen bien a las piernas o no, pues quedan para azertte ottra dozena de pares iguales a ellas y con todo cuidado esttan blanqueando el hilo, la ottra tela de lienzo es la que remitte el padre maiordomo que ya tenia conprado el año pasado de que te tengo abisado, la que para ti ba lligada // (fol. 16r) con tres lligas de hilo encarnado, una y ottra ban enbuelttas en 4 varas de esttopa, a costtado a zinco reales bara que te la pague el maiordomo de esa que le tiene para hazer dos costtales, el portte astta Madrid me ha costtado treinta reales. En el dia de oy eschribo al señor Don Agustin Alonso Martinez de Casttro se sirba mandar recojer de la aduana de Madrid el faragante [sic] de los expresados lienzos y los derixa en derechura a ese palazio vajo la rottulatta que lleba puesto en su cubiertta. Es quanto por aora tengo que abisartte y manda en todo quanto te pueda serbir, estte tu affectuoso hermano y toda su familia que esttamos pronttos a tu obediencia. Que besa tu mano, tu hermano que desea bertte. Blas Maria Rubiños.

P.D.: No dejes de responderme a la que te remitti en 24 de fevrero pasado en respuesta a la tuia de fecha 26 de enero, una y ottra de estte corriente año de 97.

Hermano Don Josef Anttonio Rubiños.

«CUADERNOS DE ESTUDIOS GALLEGOS», Tomo L, Fascículo 116, Santiago 2003. 
Villanueva de Lorenzana, Junio 18 de 97.

Hermano, habiendo llegado a es//tta (fol. 16v) tuia de fuera de ella bajo la horden que se a comunicado de la superioridad a todas las justtizias de estta probinzia con la estterilidad de fruto que se padeze por toda estta tierra y gran anbre, con la horden que me ha dado el señor merino me fue preziso pasar a la monttaña a hapremiar a los subdicttos de estta jurisdiccion el que de las medas que tubiesen las maxasen con reserba de una solamente y que se conduziese el fruco [sic] para los mercados de la ciudad de Mondoñedo como por la horden se prebiene, y no hosttantte de ponerse algun fructto en los mercados aun se experimento y estta experimenttando el llegar la anega de zenteno a 118 reales, la de maiz a 136 y la de trigo a 144 reales, pues estte ulttimo juebes aun ha pagado tu cuñada y por gran amisttad la anega de zentteno a 10 reales, y no me llegan dos para la semana, que biene a salir por 200 reales el fructto semanariamente, que asonbra semexante caresttia, pues la libra de pan de trigo y no del mexor llega a dos reales, lo que nunca se a bistto ni se presumio subzediese por estta tierra, bien enttendido que estte año si no fuera la montana, los de los bales, Mariñas y Astturias caherian muer//tos (fol. 17r) por los caminos como moscas, ya muchos se encuenttran muerttos en sus casas de hanbre con la miseria y bregüenza [sic] que les causa el pedir, maxime a mucha nobleza que ai por estta paraxe, y algunos robos y disgrazias subzeden pues por el dia y por el sol se ban a las casas de los que tienen (a la mia no tienen que benir porque el trabajo de toda la semana no me llega para tres ferrados de fructto), considera tu que sobras tendre al cabo de el año quanto mas para lo que se nezesitta.

Luego que he llegado a estte mui tuia, la expresada tu cuñada me ha enttregado dos tuias, la una de fecha cinco de maio y la ottra de veinte y nuebe del mismo, y al dia siguiente fuy a esttar con el padre maiordomo haziendolo presente el papelitto adjuntto de la $1^{\mathrm{a}}$, a quien le pedi me diese el recivo para remittirtte supuesto no tenia dado razon alguna en esa, el que me expuso haberlo executtado, si es asi o no lo saberas mexor tu que no yo. Al mismo tiempo te boy azer presente en primer lugar que con cartta que te he remettido en 21 de noviembre del año pasado de 95 le haconpañaba un recivo dado por el padre maiordomo Luna en los 28 de septiembre de el propio año /que su tenor a la lettra es el siguiente/ (de que tengo carrta tuia de aberlo recivido): «Recivi de Don Blas Maria Rubiños, vezino de Villanueva de Lorenzana dos mill settentta y un rea- 
les // (fol. 17v) y medio para paga de zientto nobenta y quattro baras de lienzo fino que de horden del Señor Yllustrisimo de Almeria se me encargaron, y para su resguardo doy el presente que firmo en el Monastterio de Lorenzana y septiembre 28 de 1796 . Fray Luis Luna». Y aora te remitto ese ottro dado hoy dia por el mismo de la canttidad de 1.714 reales y dos maravedis vellon a fin de que puedas perzebir de mano de ese señor maiordomo dicha canttidad, quedandome con el cuidado que luego que me resttittuia a estta nominada tuia de la comission con que me allo de hazer la qüenta xeneral que me pides para remittirtte, pues en el propio dia de oy buelbo a salir para la montaña supuesto conozes se aze preziso el trasporttar algunos inttereses que se puedan ganar a casa para manuttenzion de tantta boca como Dios fue serbido de darme, y grazias a el y a ti, que si no hariamos como muchos mas aun maiores que yo al doble, que es una lasttima el ber lo que pasa por esttas tierras, que los biejos que ai mui cerca de 100 años que conoze ese Señor Yllustrisima en estte curato de Villanueva esttan diziendo que el año de 10 y 69 no era pinttura para conparar al presente ni xamas se a oydo conparazion de ambre por quantas partes tienen andado sino el año 10 , sin // (fol. 18r) nombrarse ottro. Dios y su Santtisima Madre quiera que no nieve (que esttamos con el hixo), que si nieva pobres de los vibos que residimos en este valle de lagrimas. Es lo que por aora tengo que dezirtte estte tu affectuoso hermano y to/da/ su familia, que tu mano besa. Blas Maria Rubiños. Hermano Don Josef Anttonio Rubiños: «Recivi de Don Blas Maria Rubiños para satisfazion del lienzo que remitti a Almeria, un mill siettezientos y cattorze reales y dos maravedis, de los que los mill doszientos onze reales y 20 maravedis son perttenezientes al lienzo esttrecho, y los resttanttes al lienzo fino, remittido ulttimamente. Lorenzana y Junio 18 de 1797. Fray Luis Luna».

Villanueva de Lorenzana, Julio 7 de 1797.

Hermano, boy a dartte respuesta a las dos tuias segun lo ofrezido en la antterior a estta, de fecha 18 del pasado, y al conttestto de ella como de ottra que me has remittido antteriormente sin fecha, te digo en primer lugar que el terzer parrafo que en ella se contiene, quanto a Benito Ramos no es horo lo pinttado o fenxido en la que te remittio, no // (fol. 18v) quiero proseguir, mas adelantte te poderas informar de tus amigos de Mondoñedo pues aun puede que tengas alguno, que baxando por aquella

«CUADERNOS DE ESTUDIOS GALLEGOS», Tomo L, Fascículo 116, Santiago 2003. 
ciudad para estta tuia aun se me expresaron zierttos lanzes que abia echo con sus cuñados, los pobrezittos Mendres, que me ha causado muchisima lasttima, no esttube con ellos pues aun expero en Dios el abocarme. Se halla en El Ferrol con su muxer y criada gasttando lo que ottro a ganado, mira en que tiempos esttamos y lo que dan de si los ofizios, pues por los modos se biene en conozimiento del rum-rum, unos se lleban la fama y otros cardan la lana, enttiendeme como quisieres, creer en Dios a pies junttos, pues aun lo que se be no se puede creer, que la bista engaña. Al quartto parrafo que abla quanto a Gaioso, te expongo aberselo dado a leer a el mismo y echo cargo de su conttestto dixo que bien esttaba, que abia de seguir en su prettenssion, si lo hizo o no es mui regular te diese alguna nottizia. Y dando respuesta a la tuia de fecha cinco del mes de maio pasado de el corriente año, te digo en primer lugar aber prenzipiado con tu horden a enttregar al señor Don Diego de la Bega y Montenegro, // (fol. 19r) que Dios goze, el inporte del productto de fructtos dezimales de la sincura o presttamo que obttienes en la feligresia de San Esteban de Balcarria, en la manera siguiente: En los quatro de Octubre de 87 le he enttregado a dicho señor Don Diego 2.000 reales; en 11 de Julio de 88 2.400 reales; en 17 de Noviembre de 892.001 reales y 6 maravedis; en 27 de Junio de nobentta 2.400 reales; y en los 27 de Junio de 91 de la misma suertte lo hize de ottros 2.400 reales; que junttas las cinco parttidas pareze conponen 11.201 reales y 6 maravedis. En los siette de Julio de el año de 94 te habise aber pasado a la expuesta ciudad de Mondoñedo a esttar con el señor Don Diego aziendole enttrega de dos mill y ochozientos reales y que no me lo quisiera rezebir. Y en los 7 de Agosto del zittado año te bolbi a eschribir lo mismo por no haberseme dado respuesta a la antterior de lo que en ella te significaba. Y 28 de Septiembre de 95 entregue tambien de tu horden al Padre Maiordomo de el Real Monasterio de estta villa segun recivo que te he remettido, 2.071 reales y 17 maravedis vellon. De la propia suertte lo hize a nuestra sobrina, la muxer de Gaioso, en los 4 de Agosto de 96 de ottros 320 reales vellon, y en los 26 de el propio mes y año ottros 60 reales a la muxer de Anttonio Martinez, hixa de nuestra prima Anttonia Pedreira, muxer de Ramon Cabana. Tambien // (fol. 19v) lo hize al Padre Maiordomo ya expresado de ottros 1.1714 reales y dos maravedis segun se conttienen en el recivo que te remitti de fecha 18 de Junio pasado del corriente año que aconpañaba la cartta que en dicho dia te he remettido. El lienzo que te he remettido en los 26 de Marzo tambien 
pasado de estte año conpuesto la tela de 45 varas, me ha costtado la bara a 13 y medio reales, y si me tubiera algunos dias mas azer la conpra subia a mucho mas, que se a puesto mui caro, como lo hizieron todas las cosas. Las calzettas, que fueron seis pares hordinarias y cinco finas, tambien me an costtado unas y ottras zientto noventa y quatro reales (y los dos pares resttanttes son las que an echo tus sobrinas Pepa y Marica, tienen echo ottros quattro pares pero asta tantto les enbies la razon si te bienen a las piernas o que defecto es el que tienen, les mande subspender y quedan aguardando tu horden). De estopa en que fue enbueltta con la que ha ydo para ese palazio, an llebado 4 varas a razon de 5 reales cada una y treinta de portte que llebo el maragato astta Madrid hazen zinqüenta reales. Y lo mas resttantte inporte eche mano de el quando me eschribieras hiziese ropa a Pepe para remittirttelo, que ha sido una capa, chupa, calzones, camissas, calzettas, suspendiendo azer // (fol. 20r) lo demas por el abiso que segunda bed me as remettido, y con la estterilidad de el año pasado, el del presente de enfermedades de unos y ottros lo fuimos gasttando y tambien con el pleitto de la capilla de Vizente, pues se halla concluso, en difinittiba, para darse el autto, y lo tienen que azer el señor chanttre Villares y el señor Yebra, dean, señores probisores en bacantte, el provisor Casttro y el abogado que defiende me dan vuenas anumpzias, pero ni por eso dexe de balerme de amigos para que se intteresen con dichos señores por tu sobrino, bien que a lo que fuere de justticia no pienso que falten ni es de pensar, y mi ofizio da poco de si como ia te tengo abisado por no darme resoluzion a poder repettir el sittuado quanto al ayuntamiento, que me attrasa mucho en mis inttereses. En fin, no tengas pesar por lo que te faltta, que mas bale deberttelo a ti y que nosottros a lo adelantte te lo sattisfagamos, que no torzer el brazo a ottro alguno de estta tierra que lo publicase, solo por el esttado en que su Debina Magestad te ha puesto y el bien que nos azes, pues subzediendo el que Maria Santisima de los Remedios permitta salga Vizente con la capilla como deseamos, despues de sattisfechos algunos gastos del economatto que ubiere, esttara a tu disposizion como al presente estta quanto oy se ha//lla (fol. 20v) por nosottros. En mi poder se hallan 2.800 reales que me an enttregado los llebadores de tu presttamo el dia veinte y quattro de Junio pasado de este corriente año, pertteneziente al año pasado 96 . Y es ziertto aun subsisttir en dicho mi poder del restto de los de el año pasado la canttidad de unos 400 a 420 reales, pero temome el que no los gastte en fructto por no salir

«CUADERNOS DE ESTUDIOS GALLEGOS», Tomo L, Fascículo 116, Santiago 2003. 
de lo que Dios nos ha dado. En todos los partticulares que conttiene estta cartta haze la bolunttad de tu agrado como en las antteriores que te tengo eschrittas, solo te repitto por el anima de nuestros difunttos padres que repares soy tu hermano y que no tienes en el dia ottro. Dios te conserbe por muchos años para el serbizio suio, y azernos el bien que acostumbras. Que besa tu mano tu haffectuoso hermano. Blas Maria Rubiños. Hermano Don Josef Anttónio Rubiños.

Villanueva de Lorenzana, Agosto 16 de 1797.

Hermano, oy dia recivi dos tuias que me ha enttregado una vezina de estta villa, la primera de fecha 14 de Julio, y la segunda de 28 , las que conozco attrasadas por sus fechas, pues aunque e mandado la criada a Mondoñedo y a la esttafe//ctta (fol. 21r) el correo anttes, a su llegada quando hizo el regreso a estta tuia me ha expresado le habia dicho el esttafecttero no abia cartta alguna para mi, y de reconozidas una y ottra, dando respuesta a la primera te digo que en el dia de mañana, Dios queriendo, pasare a la ciudad por ber si allo en el mercado alguna persona de Vibero que yo conozca y por ella abisare al señor cura de Balcarria disponga persona de su sattisfazion que benga a estta mui tuia ha perzibir de mi mano y en nombre tuio los doszienttos quarenta reales que me hordenas le remitta por persona segura o de mi sattisfazion, lo que no are por no haberla al presente en estte pais que transitte a haquella de Vibero, y siempre que subzeda haberla en dicha ciudad como tu lo dizes se los remittire, y en su defectto le remittire cartta para que executte lo que llebo relazionado para maior seguro de uno y ottros. En quanto al papel adjuntto que conttiene ziertta adberttenzia de Benitto Ramos, marido de nuestra hermana Maria, ya te tengo propuestto mi senttir en la antterior a estta de fecha 7 de Julio pasado de este corriente año, solo si te adbiertto y te ago presente que algunos vezinos que ban de la nominada de Mondoñedo a la feria de El Ferrol // (fol. 21v) me an expresado se portta en aquella villa y su muxer como si fueran unas personas de ottro sexso echando mucho por ella, considera tu de donde podria benir el barro para hazer semexantes palazios a no ser las uñas largas, juntto con el proberbio anttiguo (para quien ganas ganador, para quien duerme y estta al sol). Repararas los tiempos en que nos hallamos y que fructtos tan barattos Su Divina Majestad fue serbido darnos por nuestras culpas y pecados para poder azer semejanttes gasttos cada uno fuera de su casa?. O Don Diego de la Bega y Montenegro, tu 
anima permitta el Alttissimo estte gozando de su beattissima presenzia? A esto nuebamente te digo que unos cardan la lana y ottros se lleban la fama, no fue el montanes pero en el dia se asegura fueron mas pronttos los ferroleses, ni tanpoco lo an sido nuestro sobrino Xabier y su hermana Bizenta, pobres menores que se hallan en posada y no se como lo pasan por haberlos echado de casa el domine Lucas, sin poder sin poder [sic] saber el porque mas que el lucrarlo todo y reirse de sus cunados? Es buen pensamiento estte? (no por ziertto) sino de un honbre del tenor siguiente. En quanto a la cosecha, esttubo un poco mejor en grano (segun dizen los labradores) que no la antterior, pero menos paxa y como estta subzediendo la faltta de agua// (fol. 22r) para los maizes, abas, pattattas, bino y casttaña, los que cojieron algun zentteno, trigo y zebada, se dettienen con el presumiendo subzeda con la cosecha presente como con la pasada, y los pobres no pueden majar por echarseles tarde la sienbra de nabos con la expuesta escased de agua y no poder culttibar las tierras para ellos por esttar tan fuerttes de la seca, y por lo mismo aun se hallan los mercados falttosos, pero no con los prezios eszisibos como astta aqui, pues el trigo el juebes pasado se benefizio en la plaza de Mondoñedo a 24 reales ferrado, el zentteno a 18 , y el maiz a 23 , y puede que aun no baliese tantto si los labradores no esttendieran la labor, que la cosecha de maiz ya esttaba perdida por faltta de el agua que aunque biniese de prontto la amettad se fuera porque le pasara la sazon de la expiga, y en paraxes lo hiban dando al ganado porque les secaba, Dios lo remedie que es el que puede, no se que prezios tendra mañana, dandome salud lo he de ber bien que astta tantto pobres y ricos maxinan xeneralmente subsisttiran los prezios, a no ser que llueba, que la faltta de maiz es la que da la caresttia en Galizia, que fue el mottibo de ella en la antterior cosecha, y tambien algun mottibo causaria el cordon, pero el peor fue el primero. // (fol. 22v) En quanto a lo mas que conttiene la $2^{\mathrm{a}}$, yo no se como aga para dartte gustto en un todo pues a su conttestto anttes de aora en repettidas carttas que es regular subsisttan en tu poder, ya te tengo dado resoluzion, pero en fin are lo que pides quanto anttes pueda. Tus sobrinas te suplican les agas el fabor de enbiarles a dezir si te biene bien o no los dos pares de calzettas que te an echo, o que faltta tienen, y quando menos que les remittas el grueso de panttorrilla y el de la canilla en un hilo o papel denttro de una cartta, pues las que tienen echas se ebidenttemente saldran de buena dura supuesto las hizieron mui tupidas, y para hazer los resttanttes pares que les falttan

«CUADERNOS DE ESTUDIOS GALLEGOS», Tomo L, Fascículo 116, Santiago 2003. 
quieren dichas medidas por ber por ellas si saldran a gustto, pues me presumo las echas lo estten, quanto mas despues las que trabaxaren teniendo las presentes. Es lo que por aora tengo de que abisartte, solo el aberle eschritto en el propio dia de oy a la donzella de el Señor Maxisttral que si por forttuna se allase en aquella alguna persona conozida suia y de su primo el cura de Balcarria, pudiendo ser la dettubiese, que por la mañana del dia siguiente esttaria tenprano alla como espero ejecuttarlo, conserbandome Dios bida y salud. Que tu mano besa, tu hermano Blas Maria Rubiños. Hermano Don Josef Anttonio Rubiños.//

(fol. 23r) Villanueva, Agosto 27 de 1797.

Hermano, en el dia de oy me hallo con cartta de el señor cura de Balcarria Don Francisco Anttonio Fernandez de Ortta, de fecha 20 de estte corriente mes y año, en que me espresa haber recivido las dos honzas de oro que de tu horden le he remittido por mano de su prima Doña Mariana Fernandez, donzella de el Señor Maxisttral de la cattedral de Mondoñedo, que en el dia 17 he dexado en su poder por no hallar ottra persona mas prontta y segura que los pudiese de rexir para enttregar en propia mano del nominado señor cura. Es lo que por aora tengo de que abisartte, y en el intterin y siempre estta a tus hordenes estte tu affectuoso hermano que tu mano besa, Blas Maria Rubiños. Hermano Don Josef Anttonio Rubiños.

P.D.: Es mui regular que tengas abiso de estto de parte de el cura.

Almeria.

En 12 de enero de 98 he eschritto a mi hermano Don Josef Rubiños la funebre nottizia de la muertte de nuestro primo Taibo, y que me abia dado parte su biuda muxer y mi cuñada que subzediera su falleszimiento en el dia 9 del propio mes y año, y como no me abia dado respuesta a ottra de fecha 27 de Agosto de 97 y ottra de 16 de Deziembre del mismo ano. //

\section{(fol. 23v en blanco)}

(fol. 24r) Coruña, Setiembre 22 de 97.

Mui señor mio y amigo sin embargo de no tener correspondencia con Vuestra merced, por las nuevas noticias y ajenzias que de todos tengo me alienta a remetirle la adjunta copia de poder y documentos que le acompañan para que con la maior eficazia y prontitud se sirba por medio de 
abogado de su satisfazion formar la correspondiente queja contra Josef Rodriguez, escribano, para que la sala le castigue segun corresponde, y todo luego que se presenten los autos sobre que recaio que no menos lleba el dador para que con vista de todo se me restituia mi onor que siempre tube, y tome con dignas probidencias contra aquel. Cuio encargo como cosa mas principal que todos debemos apetezer en nuestros empleos reencargo a Vuestra merced y el coste que tubiese o el dinero que Vuestra merced me abise, pondre en manos de su hermano o su tio. Nuestro Señor guarde a Vuestra merced muchos años que le desea su seguro servidor que su mano besa, Blas Maria Rubiños. Señor Don Francisco Corujo y Somoza.

En 10 de Octubre de dicho le bolbi a eschribir y le remitti una probision con las delixencias pratticadas que era de [sic].

Santtiago, Septtiembre 24 de 97.

Reberendisimo Padre Don Francisco Manuel de Puga. Mui señor y dueño mio, dias haze tengo en mi poder compuesto para remitir a $\mathrm{Su}$ Paternidad un fa//rangote (fol. 24v) compuesto de zien baras de lienzo fino que tenia encargado el Padre Mayor Abad de este Real Monasterio Don Fray Benito Martinez, y de horden suia y de la señora Maria pase a la ciudad de Mondoñedo a comprar de ellas la pieza de sesenta baras y tercia, pues solo ba por las sesenta baras, y no pude allar cosa de mi gusto mas que tan solamente un pieza por ser ya tarde para hazer dicha compra, es un poco mas moreno que el que tenia la señora Maria, que es la de quarenta baras que la acompaña, pero en quanto a la calidad me pareze no dejara de gustarle, y otra qualesquiera persona que lo reparen, pues uno y otro es todo gallego, y a tenor antes de haora la notizia ya lo solicitara tan blanco como el que he conprado para su Señoria el Señor Yllustrisimo de Almeria y su probisor, mi hermano, y asi en este particular como en otro qualesquiera que a Su Paternidad se le ofrezca e yo pueda serbirle no tiene mas que noticiarselo a la espresada señora Maria, que se executara de pronto, desde cuio tiempo andube solicitando persona segura que quanto mas antes lo pudiese poner en su poder dexando encargado a halgunos amigos de aquella expuesta ciudad que siempre que ubiese alguno que fuese para esa me diesen abiso, y como en el dia de hoy la tubiese, que el dador de esta que es uno de ellos, fuese en compañia de los señores

«CUADERNOS DE ESTUDIOS GALLEGOS», Tomo L, Fascículo 116, Santiago 2003. 
canonigos de la cathedral de la ya citada de Mondoñedo que ban a dar besita de parte de el cabildo al Señor Yllustrisimo que se halla electo para dicha ciudad y su Obispado, pase a molestarle para que lo executase como asi // (fol. 25r) me lo ofrezio azer, bajo cuio supuesto tambien suplico a $\mathrm{Su}$ Paternidad que en lo que pueda lo ampare y proteje en su pretension, que a la bista espondra lo propio que tambien le suplica dicho Padre Mayor Abad por haberselo pedido yo, reserbado para Su Paternidad. La señora Maria me espreso pusiese en su noticia que el Padre Carrio que haze de maiordomo que es lo mismo que antes era, y se la apurar que aun es peor que a no ser por el ya citado Padre Mayor Abad ya no estaba en el sitio, y que Su Paternidad le mandase preguntar a este como hiba con ella, esto es aziendose neutral de la adbertencia que ba espuesta por que no se agan cargo fue de aca semejante preposizion, y quando llegue a noticia de ella se halla Su Paternidad en casa de el señor su sobrino el señor cura de Mandra, que ha de hir a berle porque le tarda lo bastante y que en el ynterin reciba de su parte mill esprisiones, y que se sirva comunicarlas tambien al señor Roque. De parte de mi partida y la mia hazemos la misma remesa quedando en el ynterin y siempre a los preceptos de Su Paternidad rogando a Dios comserbe su salud de Vuestra Paternidad por dilatados años de esta mui suia y suio que su mano besa, su maior serbidor y affectuoso de corazon. Blas Maria Rubiños. //

(fol. 25v) Almeria y febrero 10 de 98 .

Hermano, me hallo con la noticia de haver fallecido el dia 14 del pasado ese Señor tu Yllustrisimo, con cuia noticia se le ha hecho en este Real Monasterio tres funciones consecutivas en dias distintos por su anima, quedando de hacerle sus honrras con sermon segun se me asegura, pero se estan aguardando algunos apuntes de esta para haver de componerlo. Dios permita este su anima en descanso, y las nuestras quando emprendamos igual jornada. Conozco las grandes ocupaciones que podras haver tenido y tendras a la sazon, pues basta este a tu cargo el obispado entero, y por lo propio no me quejo de la falta de contestacion a las mias que te tengo escrito, espero lo hagas quando tengas una horita de vagar, pues me tiene en cuidado, y a tu cuñada, maxime en esta ocasion para ver como te $\mathrm{ba}$, avisandome si algo se te ofrece ahora que te hallas huerfano, para proceder con tu aviso a lo que me preceptues, que siempre a ello estubo y esta pronto este tu mas apasionado hermano y seguro servidor que tu mano 
besa, Blas Maria Rubiños. Hermano Don Josef Anttonio Rubiños. //

(fol. 26r) Almeria.

Villanueva, Marzo 20 de 1798.

Hermano, recivi la tuia de fecha 23 de febrero pasado de este corriente año, y por lo que de ella reconozco beo gozas perfecta salud de que queda sumo gusto a todos los de esta mui tuia.

En quanto al asistimiento de las funziones funebres que se han echo en este Real Monasterio por el anima de ese Señor Yllustrisimo Prelado que ha sido en esa diocesis, me pareze que seriamos todos, tanto yo como como mi familia, unos ydiotas a no executar el asistimiento personal de las tres funziones, y para que lo conozcan mas vien a la ultima de ellas tambien hize asistir a la criada de casa, pues todos gozamos de un mismo veneficio (y me parezia que esto de suyo se podia entender sin dartelo al eschrito).

En esta y ciudad de Mondoñedo se corrio que supuesto dicho Señor Yllustrisimo no tenia pieza alguna que adjudicar a su familia y que el prebisorato que has regentado en esa se te habia dado por la Camara de $\mathrm{Su}$ Magestad (que Dios guarde) hera bitalizio, y lo propio la ajenzia de Roma, pero beo me anumpcias lo contrario.

En fin, abisame en tiempo si es que // (fol. 26v) agas la salida para Madrid u otra parte, de lo que quieras execute, pues si fuera tu gusto te remitire para aquella de Madrid lo que mandes por los gallegos que salen para aquella tierra u otra qualquiera persona que sea segura.

En el dia catorze de este corriente mes entregue a nuestra sobrina Maria los doscientos reales que me dispones lo execute, pero dudo mucho sea para lo que contiene la carta que te ha eschrito como yo le dixe, mas regular sera para lo que acostumbra ella y su marido.

En quanto al balor de fructos asta haora en los mercados, el prezio de el trigo se alla el ferrado a 22 reales, el de zenteno a 15 y a 16 , el de maiz a 18 , habas a 20 siendo blancas y las pardas a 17 y 18 reales, bino de el Ribero siendo bueno a real quartillo, y el de la tierra por menor a 24 maravedis, carne en esta villa a real libra y en la ciudad a 10 quartos, pescado poco y caro, azeite, manteca, grasa y sebo muy carisimo por andar escaso todo, y cada bez mas con las malas noticias que corren // (fol. 27r) de los buenos franceses. Que te estima y ber desea en vida sana y salud, tu hermano Blas Maria Rubiños. Hermano Don Josef Antonio Rubiños.

«CUADERNOS DE ESTUDIOS GALLEGOS», Tomo L, Fascículo 116, Santiago 2003. 
Almeria.

En 31 de Julio de 98 eschribi a mi hermano dandole parte haberse muertto el chiquitto que ha quedado de Anttonio Cora y no quedar de estte ni de su madre, nuestra madasttra, eredero alguno, no poderle eschribir por el mottibo de los sortteos de melizias. La muertte de Valledor y su pasaxe como habia sido, como despues de su muertte fue su hierno Santtiago solizittar el numero para el ottro hierno el astturiano. Que se halla el inporte de frutos del presttamo caidos en el San Juan pasado, siendo fruttos de 97 , y el resto de los de 96 que disponga a donde quiere se le ponga. //

(fol. 27v) Cartta a Don Agusttin Martinez de Casttro a Madrid, sobre eschritto de ella a Don Francisco de Trabeso, thesorero de la reduzion de Vales. Carrera de San Geronimo. Madrid.

Señor Trabeso.

Dueño y mui señor mio, no obstante de haber pasado largo tiempo que no he tenido noticia de su importante salud, no por eso he dejado de tenerla por su sobrino Don Manuel Antonio Trabeso a tiempo que venia de esa villa y corte de Madrid, a quien suplique escribiese a Vuestra merced a fin de que se sirbiese faborecerme en la suplica que contiene la adjunta del sobredicho, con otra igual que tambien yo le hago, para que de reconocido el despacho adjunto se sirba disponer su pronto cumplimiento, que todo lo que gaste con su abiso entregare a la persona que se sirba señalarme, sirbiendose disimular semexante atrebimiento, y man//darme (fol. 28r) en quanto comtemple pueda serbir a Vuestra merced este su seguro y obligado sierbo que su mano besa, Blas Maria Rubiños.

P.D.: En este testimonio escribo a Almeria a mi ermano el Doctor Don Joseph Antonio Rubiños haciendole presente la molestia que hago a Vuestra merced por esta.

Villanueva de Lorenzana, Septiembre 24 de 803.

Madrid.

Villanueva de Lorenzana, Noviembre de 1803.

Señor Agusttin Alonso Martinez de Castro.

Dueño y mui señor mio, recivi la mui faborezida de Vuestra merced aconpañada con el despacho requisittorio, delixencia practticada a su conttinuazion con Don Manuel Ruy Lopez de la Caenlle y mas que 
conttiene porque doy a Vuestra merced las mas hattenttas y debidas grazias. Por el recivo adjuntto conozera aber enttregado en el dia de ayer a su sobrino Don Manuel Anttonio Gonzales Trabeso los quarenta y dos rerales y veinte y dos maravedis vellon para que le diese a Vuestra merced con mas pronttualidad que yo la de sattisfazion, lo que he executtado por mano del sobredicho por no aberme señelado Vuestra merced en la suia persona alguna a quien debia azerlo como en la antterior a estta se los suplicaba, y en el intterin y siempre puede Vuestra merced // (fol. 28v) mandar a estte su fino afectto y seguro serbidor que su mano besa, Blas Maria Rubiños.

Ojo.

Copia de cartta eschritta a Vizente en respuesta de la suia eschritta de Madrid de fecha 23 de Maio de 806.

Villanueva de Lorenzana, Maio 31 de 1806.

Hijo Don Vizente Rubiños.

Recivi la tuya con sumo gustto por saber de tu salud aunque lo basttantte tarde, pues me pareze lo que as echo conmigo es mui regular lo aigas echo con el señor tu tio de Almeria no obsttantte de abertte abisado lo basttantte anttes de salir de estta, y lo propio en la villa de Meira, y as falttado a lo ofrezido, pues con dos lettras que expusiesen he llegado a estte lugar bueno o de tal suertte abia lo basttantte y no tenernos con el cuidado en que nos has tenido astta la ora presente. Tu te pareze que por esas tierras es lo mismo que las de Santtiago, Tuy, Viso, etcetera, ten presente los abisos que te tengo dicho y no te bisttas de tu capricho que no as de salir mui luzido, ber, oir y callar, y no ay que conttradezir a cosa ninguna, que no esttas en tu pattria para echar por ella, y acuerdatte y ten siempre presente los apuntes que as llebado, pues // (fol. 29r) la tuia no indica los tubieses presentes en todo el camino que as dejado attras, pues si Dios te conserba la salud para proseguir la jornada quanto lo /que/ aun te faltta para el conpletto de ella, aun es peor. Faltta aora me expliques o expongas el porque no as eschritto astta aora, y si as echo lo propio con el señor tu tio pues de dos que tiene alla mias como a ti te constta de aberle abisado tu salida y viaxe, astta aora no tube resoluzion alguna y quien ha sido el mottibo el buen modo que as tenido de azer lo que te a mandado, y lo propio tu padre, y por estto mismo pienso ten bien lo que me abisas te subzedio con Don Agusttin, provisor, su sobrino. Por lo que respectta ha ordenartte en esta, ni Don Agusttin ni tu tio ni ottro alguno puede saber

«CUADERNOS DE ESTUDIOS GALLEGOS», Tomo L, Fascículo 116, Santiago 2003. 
mexor que tu si lo podras hazer o no, ad lo mejor que te tubiere conbeniencia y toma resignuazion como es debido, suplicando a Su Divina Magestad te la de y a mi y mas para serbirle, estto es en primer lugar y a lo adelantte lo que fuere de su santisimo agrado, que aziendo lo conttario ya puedes conozer el exiptto que te puede sobrebenir, y a todos nosottros, pues ya no eres niño por seres maior de los veinte y cinco años. En quanto a posada y comida, no pienso te faltte cosa alguna pues quien te a puesto en ella no a de dejar de cunplir con todo, te abiso nuebamente que no tienes desculpa alguna, no dejes de eschribirme todos los correos o a lo menos cada ocho dias, y lo mas tardar 15 para saber como te allas, y no te aflijas, pues Dios sobre todo, y cuidado con ello, no agas como asta ha//qui (fol. 29v), y si tienes alguna razon de dicho tu tio o no tanbien me lo aras presente sin perdida de tiempo para saber el mettodo que se pueda tomar a lo adelantte, pues enemigos y emulos no falttan por todas partes y a quien se puede echar la culpa esha [sic] mala madre (y estta general es) la enbidia. Dicha tu cartta me l'a enttregado tu madre con ottra de tu tio el cura del Biso, quien se alegro mucho con tu biaxe y te esttaba aguardando bolbieses a Tuy para ordenartte de missa, y lo propio el amigo Don Gabriel y mas de quienes e tenido razon en tiempo para podertte poner en aquella ciudad, cuia me a sido enttregada ayer noche, siendo la ora 9 de ella, luego que hize el regreso a casa, y tantto tus hermanas como tu cuñada y sobrino Pepe ya sabian su conttesto por aber pasado abrirla dicha tu madre, y a tiempo de apearme de la mula me lo expuso dicho tu sobrino, y de una y ottros reciviras memorias que te debuelben, y que te allen con perfectta salud como cada uno la desea para si, aunque el muchacho Pepe no se alla bueno. De mi parte no te digo nada, sino que Dios te conserbe con ella el tiempo que fuere de su santisimo agrado, quien bien te desea, tu afectuoso padre Blas Maria Rubiños. //

(fol. 30r) Cartta para Vizente a Almeria. Julio 11 de 806.

Hijo, a la hora de dos menos quartto de la tarde de oy dia recivi la mui apreziable tuia de fecha 27 de el mes pasado de Junio por la que reconozco as llegado con perfectta salud a pressencia de el señor tu tio (en la antterior de que es respuesta a estta), tu madre y hermanas e yo nos emos alegrado muchissimo pero al mismo tiempo nos queda el senttimiento de ber en la conformidad en que le as allado, que jamas se a explicado como 
tu lo hazes Dios y Maria Santisima de los Remedios se lo de para bien de su alma, y lo propio a todos nosotros. Expero en ella el pasar en el dia de mañana a bisittar su santa capilla dandole las grazias por tu llegada, y al siguiente dia, domingo, buscar sazerdotte que cantte a la Soberana Reina una missa por interzesion del dicho tu tio suplicandole le de el remedio y alibio que fuere de el agrado de su Santissimo Hijo en los achaques abittuales que se alla padeziendo. En quanto al dinero ya enttregue de ellos al escribano Monttoutto mill reales que le esttaba adeudando, pero si no ubiere ottro remedio sera preziso salir de lo que ubiere para dar a dicho tu tio la sattisfazion que es debida, pues ellos ya se los esttaba adeudando de quando te as ordenado de epistola, y siempre admas de lo que io podia junttar como tu sabes era el unico que en estta villa puede serbir de redenttor a qualquiera amigo, pues por el ofizio no se puede ganar para carne con // (fol. 30v) tantto trabajo como da el ayuntamiento y el Rei con tanttas ordenes y sortteos sin baler marabedi como tu lo as bisto y reconozido. El que le eschribe desde estta a tu tio, ten de seguro es tu hermano, que las mismas palabras que consttan en la tuia que mis gasttos son /con/ poco onor y jentes de poco meritto, esttas palabras poco tiempo aze las echo en cara a tu madre, discurro que todo le deben y nada le pagan pues a si mismo se estta despreziando, no conoze el bien que le esttan aziendo que en el dia su manuttenzion, la de su hijo y dos perros no gasttan fructto alguno sin lo mas que se le da, y la buena de tu cuñada ottra buena lengua, que tanbien se por donde se alla lo que abla, pero yo ni a uno ni a otra le pedi ni pedire sattisfazion alguna. Tenlo para conttigo que los dos si bieran tus hermanas como ellos tienen inttenzion no querian otra cosa, y lo propio a tus padres ban discubriendo buena ylaza, yo no se que gasttos fueron esttos de poco onor y jentte de poco meritto, pues en estta tu sabes bien no ai juegos ni banquettes que entre jenttes biles, y ba que esttos son los de poco meritto, pues si alguno come y bebe si no es por un tittulo es por ottro, pues ellos lo pagan bien porque unos con paja, ottros con leña, otros con enttrecosttos a costtillas, capones, carnero y ottras frioleras que lo coman o beban es mucho, estto no es gasttar con poco onor y con jentte de poco meritto como se deja ber mui bien, y no abra ottra mala lengua como la suia que diga ottro tantto, pero si buelbo a dezir que todo ello sera mas // (fol. 31r) por enbidia que por caridad, y concluio en estte partticular, y no me dara cuidado si el propio tu tio te apuntta la expezie nuebamente que le hagas cargo de lo relazionado, y

«CUADERNOS DE ESTUDIOS GALLEGOS», Tomo L, Fascículo 116, Santiago 2003. 
aun no lo explico todo que mas bale callar que mucho ablar. Dicho tu hermano esta aguardando respuesta de la cartta que ha eschritto a tu tio segun me lo significo que es en la que acaso fueron semexantes notizias para conseguir lo que le pide, yo no se si sera dinero u ottra cosa pero me pareze sera aquel. Por lo que respectta a Silbesttre da Vila, enttrego quando fue Pepe buscar el pan los sesentta reales, quando bino le he pregunttado y me lo nego el expresado se lo abia de traer para el juebes siguiente y anttes de haverme expuso el chalanero le enttregara los zinqüenta reales por ti, por lo que esttas solbentte con el, quien me a dado muchas expresiones para ti para que te las mandase quando te eschribiese. Quantto al harriendo a dicho tu hermano le he preguntado por el y me dio por respuesta aber esttado con el primo y pregunttandole por el expresara se le quedara por olbido en casa, que lo remitiria por primer ocasion de conducttor, que no se quando sera pues bien sabes quienes son. En quantto a las lettras en el mismo dia que las recoji que fue el 23 del pasado, te las remitti a poder de el señor tu tio certtificadas por el correo de que ha de benir a mi mano recivo suio al pie del sobre eschritto, pues por ellas se reconoze no tube omission alguna en la axenzia como tu me significabas, las que conttenplo en tu poder desde el dia 5 del corriente, y lo // (fol. 31v) mas tardar el 7, de que me daras abiso para mi gobierno si es que no lo pueda hazer el mismo tu tio. Ygual adbertenzia te digo que si te encargo alguna adberttenzia, como tu azes, la tengas para ti y no se la apunttes a tu tio, pues como estta tan malitto no se como lo tomara, y mas bale callar que mucho ablar. Yo de Gaioso jamas le eschribi cosa alguna ni bueno ni malo si no es que me lo preguntte. Rezibiras memorias de todos los de estta por no andar uno a uno, de casa de Monttoutto, Caracaba, Loureiro, y de tu amiga Juana que ya oy fue a segar a Rezemill con la mas jentte. Tu padre que tus aumentos desea. Blas Maria Rubiños.

P.D.: Si puedes, no quisiera biese la cartta tu tio por lo que te apuntte, de estta puedes dezirle su conttesto si lo allas por conbeniente. Hijo Don Vizente Rubiños y Moscosso.

Sobre eschritto:

A Don Vizente Rubiños y Moscosso, presbitero residente en la ciudad y obbisppado de Almeria. // 
(fol. 32r) Xettafe.

Villanueva de Lorenzana, Julio 26 de 1806.

Amigo Manuel de Santte, estta sirbe dezirtte si te hallas con tres mill reales vellon los podras poner de mi horden en poder y mano de el señor Don Agusttin Martinez de Casttro, tesorero de la Real Caxa de Redenzion de Bales Reales, tiene su casa de residenzia en la villa y cortte de Madrid, carrera de San Geronimo, y anttes de azerlo me daras habiso sin perdida de tiempo para yo poderle eschribir, que con recivo que me remittas de dicho señor los enttregare ha tu madre o a tu tio Francisco a la bistta sin dettenzion alguna, y de estta suertte te libertto el que bengas con cuidado con ellos por el camino, y si tu bieres que no los tienes, qualquiera ottro vezino que lo quiera hazer remittiendome recivo del Don Agusttin, los enttregare en estta a quien se disponga. Tendras cuidado con la antterior a estta que ba firmada de Pepe quantto a tu hermano Juan, pues de 4 personas que teneis alla, sera milagro el no cojer una de ellas para que dicho tu hermano quede libres [sic] por estta, que de ora en ora Dios mexora, y asi lo permita. En la ora presente en tu casa no ay mas nobedad que la consabida, sino que tu madre se halla mui apesadumbrada por tu hermano Juan, y a la berdad, qualquiera de las // (fol. 32v) liebres attras expresadas al recivo de estta ya puede esttar segura, si es que los Candias no les ayan habisado por aberseles remittido la requisittoria para recojer qualquiera de ellos que fuese sufiziente para el real serbizio, pues uno de ellos soy nottizioso se halla en la siega en conpañia de aquellos que son los Candias, por que no te equiboques te lo pongo asi claro.

Responderas a todo estto sin perdida de tiempo tantto al dinero como al qüentto de tu hermano Juan por que acaso no le cojan al pobre en descubiertto, que por estta ya aremos por el todo lo que se pueda, a quien daras memorias de mi parte, buelbo a dezir si puedes executtaras la respuesta ha buelta de correo. Tu affectuoso amigo Blas Maria Rubiños.

Sobre eschritto:

A Manuel de Santte, residentte en casa de Don Manuel Tornos. Por Madrid. Xettafe. //

(fol. 33r) Villanueva de Lorenzana, Agosto 1 de 1806.

Vizente, recivi la tuia cosa de la una de la tarde de (de oy dia) por mano de el hijo del Cacaritto, que ha enttregado a tu hermana Pepa y estta ha mi, la que de reconozida no nos hemos hallado gusttosos con la nueba

«CUADERNOS DE ESTUDIOS GALLEGOS», Tomo L, Fascículo 116, Santiago 2003. 
nobedad de la llegada a esa de Granada, Dios permitta que tantto tu tiyo [sic] como tu os resttablezais en la salud que cada uno para si desea lo que suplicamos a la Virgen de los Remedios y el Carmen hos la conzedan de Aquel, a la antterior tuia que recivi con fecha de 27 del pasado mes de Julio en derechura ha Almeria que debia estar en tu mano el 26 primero como expones has salido de aquella para esa en 11 del propio mes, alli se estara quietta con ottra que he remittido a tu tiyo con fecha 22 del propio mes en que le expresaba haber llegado los de Balcarria con el inporte del presttamo y que de ellos se hallaban en mi poder cinqüenta doblones o tres mill reales que no quiso Azebedo librarlos en poder de Don Agusttin por no tener modo para ello, y que no sabia como le abia de poner 200 reales que tenia en su poder de dicho señor por mottibo de que anttes mandaba el dinero a Madrid y aora tiene horden de derixirlo al Ferrol para la tropa, y por eso e dado en acuerdo de eschribir al de La Senrra, a Xettafe co//mo (fol. 33v) constta de la copia de cartta adjuntta que aconpaña a estta de que tambien habise en la que enbie a dicho tu tio. De lo mas que me preguntas te tengo dado razon por aquella y aora te digo que uno de estos dias me expuso tu hermano le habia remittido tu primo Pepe de Riottortto el arriendo que habia echo y paraba en su poder, al que le ha dicho me lo enttregase para juntarlo a los mas papeles, y expreso executarlo bien que astta haora no lo hizo, pero lo ara. Le expuse me eschribieras y no se dio por conttentto porque aun no le as eschritto cartta alguna ni menos el tiyo despues que te has marchado, hizele presente apuraba por el dinero, a esto me respondio que nunca fuese lleno de el, que nunca Dios se lo diese, por cuio dicho conferir mexor fuese el que contiene la antterior a estta y asi tantto tu como tu tiyo podereis eschribir a Almeria oi las remittan a esa si anttes de salir de casa no abeis dejado orden a Parrazia que lo executtase. En quanto a los abittos, la sottana segun me expuso tu madre y tu hermana Pepa estta en ser, pero el mantteo lo an desecho en manttillas para Anttonia y Pepa Anttonia. Tanpoco me expones que mal tienes o si es la tierra que no te gustta, siendo estto, hallandose como se halla tan apurado con sus achaques tu tio, que dira el Mundo y quien lo posee el dexarlo y benirse sin que primero prezediese resttaurarle Su Divina Magestad su salud o a el llamarlo para si, reparatte bien anttes que lo agas ni executtes semexante pensamiento, // (fol. 34r) ten presente el bien que te hizo y ara a lo subzesibo, bastta clamar tantto por tu persona para juntto a si y no por ottro sobrino ni sobrina alguna 
(pues basttanttes ay). Y aunque tenga alguna inperttinenzia no la causa el, sino sus achaques y berse en tierras esttrañas sin pariente alguno, y aora que Dios fue serbido estares a su pressencia peor que peor cuidado. Con estto desbia semexante pensamiento o locura de tu cabeza como te lo suplico (pues aora ya pasas de niño) tantto como tu padre, como por la passion y muertte de Nuestro Redenttor Xesucrisptto, no nos des a todos los de esta semexante senttimiento, que puede ser baian unos tras ottros, o delantte unos y despues los ottros. No te digo mas, enttiendelo como debes pues no eres bobo y no puedo ablartte mas claro, bastta sea tu tio carnal, y por el tantto yo como tu y mas de esta casa si somos alguna cosa es por su inteuzion y no por padres y abuelos, etcetera, mucho tenia que explicarte, lo omitto astta ottra ocasion, no dexes de ensignuarme todos los correos la salud del expresado tu tiyo que a faltarme me daras ottra enfermedad como la antterior, o acaso la muertte, ten presente el ser hijo de obedienzia que a no ser tus padres y primero tu tiyo no eras // (fol. 34v) sino un bil gusano de la tierra como tu no ignoras sino es que te agas un insinsatto. Muchas mas cosas tenia que dezirtte, las omito por aora, repara tu esttudio y tenlo presente, y donde no alcanze tu enttendimiento no falttan por todas partes personas doucttas que desengañen lo que debe hazer siempre que se quiera buscar o solezittar, etcetera. Por ulttimo no eres niño, ad lo que debes como hijo y sobrino de obedienzia pues bien sabes la conbenienzia a que Dios te ha llegado, no te digo mas que Aquel te conserbe la salud que fuere de su sagrado agrado, y no mas que te bastta, tu padre Blas Maria Rubiños.

Hijo Vizente Rubiños y Moscosso.

Se escribio a Don Agustin en 16 de Agosto de 86 para que reciviese de mano de Manuel de Sante 3.000 reales para entregar a mi hermano el Lizenciado Don Jose Antonio Rubiños.

Otra en dicho dia al expresado mi hermano avisandole de lo contenido de lo que cita la anterior.//

(fol. 35r) Villanueva, Julio 11 de 1807.

Hermano, despues de deseartte la perfecta salud que cada uno de estta mui tuia desea para si, y lo propio a tu sobrino Vizente, te doy nottizia haberensem'enttregado en el dia 9 por su tarde los 4.000 reales renta

«CUADERNOS DE ESTUDIOS GALLEGOS», Tomo L, Fascículo 116, Santiago 2003. 
pertteneziente ha los fructtos del año pasado de mill ochozientos seis, y en estte mismo dia eschribo a Manuel de Sante que teniendo dicha canttidad la ponga en poder y mano del Señor Don Agustin Martinez de Casttro, que con recivo de estte que se me remita los enttregare en estta a quien me disponga, y lo propio ago al Señor Don Agusttin para que se sirba rezebirlos y los tenga en su poder a tu disposizion con adberttenzia que si dicho Manuel de Sante al prontto no se halla con ellos y los tenga ottro vezino, haga lo mismo que el debia de azer por que no se attrase el xiro de ellos. Todos los de estta rogamos a la Virxen del Carmen, a la de los Remedios, y a la Pattrona de la de Valdeflores te conserbe su Dibina Magestad la salud que fuere de su agrado. Es lo que ocurre a tu affectuoso hermano que tu salud desea y besa tu mano Tu hermano Blas. //

(fol. 35v) Julio 11 de 1807. Señor Don Agusttin Martinez de Castro.

Dueño y /mui/ señor mio, en este dia doy nottizia a mi hermano Don Josef Anttonio Rubiños, residentte en la ciudad de Granada, el haber dispuesto a Manuel de Santte, vezino de la parroquia de San Justto de Cabarcos, de la jurisdiccion de estta expuesta villa, pusiese en manos de Vuestra merced la canttidad de quatro mill reales vellon, los que se sirbira rezibir para que quando gustte mi hermano use de ellos a su bolunttad, que con recivo de Vuestra merced abonare a dicho Santte en estta mui suia, sirbiendose desimular tantta molestia como le causamos, y mandar en lo que conttenple pueda serbir a Vuestra merced estte su affectuoso seguro servidor que su mano besa, Blas Maria Rubiños.

Ojo.

En estte mismo correo y en dicha fecha eschribi a Manuel de Santte pusiese el inporte de los 4.000 reales en poder del Don Agusttin, que con recivo de estte enttregaria en estta a quien dispusiese, y no los teniendo solizittase persona de estta que los pudiese enttregar a dicho señor, que yo aria lo propio exibiendome el recivo, y puestto ottro ha su conttinuazion para mi seguro remittiendolo el poder del maiorazgo y la obligazion del hermano de Marcos para su brebe cobranza. //

(fol. 36r) Agosto 22 de 807.

Eschribi a mi hermano Don Josef Rubiños aberle eschritto en 11 de Julio pasado de estte corriente año hallarense en mi poder los 4.000 rea- 
les perttenezientes a los fructtos de 806 de su presttamo y en el mismo dia haber eschritto a Manuel da Senrra que hallandose con dicha canttidad la pusiese en poder de /el señor/ Don Agusttin Martinez de Casttro, que con recivo de este que me remittiese los enttregaria en estta a quien aquel dispusiese habisando de igual forma a dicho señor para su recaudazion, y habiendo prezedido te lo comunicase para tu gobierno de que me hallo descubiertto de las respuestas de todos tres quando esttaba aguardando el recivo para la enttrega de dicho inporte, y lo peor que ha sido una obligazion que remitt[i] a Manuel de Sante de parttido de dinero para su cobranza de otro vezino suio que lo estaba adeudando a otro mio de aca, y si se perdio no se como ha de ser, y de todo, uno y otro, por no tener nottizia no estoy mui conttentto y nuebamente eschribo en estte correo al Sante y al señor Don Agustin para que aquel haga la enttrega a estte de dicha canttidad dando el recivo para su seguro, y enseguida sattisfazerlo en estta a quien el Santte disponga, que te sirba de /segundo/ abiso, pues aqui no ubo dettenzion en ello supuesto se de ciertto que tu sobrino Josef las echo por su mano en la balixa del conbentto. Es lo que obcurre, etcetera.//

(fol. 36v) Agosto 22 de 807. Señor Don Austtin Marttinez de Casttro.

Con fecha 11 de Julio pasado de estte corriente año eschribi a Vuestra merced haber dado nottizia a mi hermano en dicho dia a la ciudad de Granada el haber dispuestto a Manuel de Santte, de estta vezindad, que se halla en Getafe, pusiese en poder de Vuestra merced la canttidad de 4.000 mill reales vellon a disposizion de aquel, que con recivo de Vuestra merced abonaria en estta a dicho Sante, de la que no tube conttesttazion ni menos de mi hermano ni del Sante, es mui regular que la faltta de todo ello consistta en la esttafectta de que me dara habiso sin perdida de tiempo. $\mathrm{Y}$ en el propio dia de hoy buelbo avisar a mi hermano del subzeso como lo ago a Vuestra merced, y lo propio al Sante para que executte la enttrega de dicho inporte en su poder, sirbiendose disimular tantta molesttia como le ocasionamos los dos hermanos, y en el intterin y siempre queda a sus hordenes estte su menor serbidor, que su mano besa.

Dicho dia, mes y ano. Manuel de Santte.

En el dia 11 de Julio pasado de estte corriente año te eschribi expresando que si te hallabas con quatro mill reales los pusieses en poder del señor Don Agusttin Martinez de Castro, residentte en Madrid, que con

«CUADERNOS DE ESTUDIOS GALLEGOS», Tomo L, Fascículo 116, Santiago 2003. 
recivo de estte que me re//mittieses (fol. 37r) los pondria en poder de tu madre o de quien dispusieses, y no te allando con ellos al prontto solo zittases persona que lo executtase, que a la respuesta de ella aria lo propio que llebo dicho, en dicha cartta te remittio Pepe un poder de Salbattierra con una obligazion echa por uno de los hermanos de Marquete para su cobranza supuesto jamas lo pudo conseguir en esta del sobredicho, de que de uno y otro no tube razon alguna ni menos de Don Agusttin ni de mi hermano, no se si traspapelarian las carttas en el correo pues el attraso puede de el, y de la nobedad que ubiere me la comunicaras para mi gobierno sin dejar de poner los quattro mill reales en poder de el señor Don Agusttin, a quien nuebamente le eschribo los recoja y tenga a disposizion de dicho mi hermano, y tu lo aras a mi, a quien debo enttregarlos en estta tuia, los de tu casa. Por lo de aora quedan sin nobedad como los de estta y la de Pepe, los que te mandan memorias, etcetera. 